Atmos. Chem. Phys., 17, 12031-12050, 2017

https://doi.org/10.5194/acp-17-12031-2017

(c) Author(s) 2017. This work is distributed under

the Creative Commons Attribution 3.0 License.

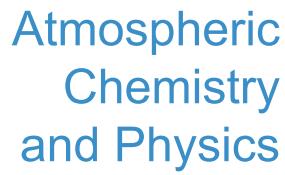

(c) (i)

\title{
A modeling study of the nonlinear response of fine particles to air pollutant emissions in the Beijing-Tianjin-Hebei region
}

\author{
Bin Zhao ${ }^{1,2,3}$, Wenjing Wu ${ }^{1,2}$, Shuxiao Wang ${ }^{1,2}$, Jia Xing ${ }^{1,2}$, Xing Chang ${ }^{1,2}$, Kuo-Nan Liou ${ }^{3}$, Jonathan H. Jiang ${ }^{4}$, \\ Yu Gu${ }^{3}$, Carey Jang ${ }^{5}$, Joshua S. Fu' ${ }^{6}$, Yun Zhu ${ }^{7}$, Jiandong Wang ${ }^{1,2}$, Yan Lin ${ }^{8}$, and Jiming Hao ${ }^{1,2}$ \\ ${ }^{1}$ School of Environment and State Key Joint Laboratory of Environment Simulation and Pollution Control, Tsinghua \\ University, Beijing 100084, China \\ ${ }^{2}$ State Environmental Protection Key Laboratory of Sources and Control of Air Pollution Complex, Beijing 100084, China \\ ${ }^{3}$ Joint Institute for Regional Earth System Science and Engineering and Department of Atmospheric and Oceanic Sciences, \\ University of California, Los Angeles, CA 90095, USA \\ ${ }^{4}$ Jet propulsion Laboratory, California Institute of Technology, Pasadena, CA 91109, USA \\ ${ }^{5}$ U.S. Environmental Protection Agency, Research Triangle Park, NC 27711, USA \\ ${ }^{6}$ Department of Civil and Environmental Engineering, University of Tennessee, Knoxville, TN 37996, USA \\ ${ }^{7}$ School of Environmental Science and Engineering, South China University of Technology, Guangzhou 510006, China \\ ${ }^{8}$ Norwegian Institute for Water Research, Oslo, 0349, Norway
}

Correspondence to: Shuxiao Wang (shxwang@tsinghua.edu.cn)

Received: 7 May 2017 - Discussion started: 31 May 2017

Revised: 12 August 2017 - Accepted: 4 September 2017 - Published: 10 October 2017

\begin{abstract}
The Beijing-Tianjin-Hebei (BTH) region has been suffering from the most severe fine-particle $\left(\mathrm{PM}_{2.5}\right)$ pollution in China, which causes serious health damage and economic loss. Quantifying the source contributions to $\mathrm{PM}_{2.5}$ concentrations has been a challenging task because of the complicated nonlinear relationships between $\mathrm{PM}_{2.5}$ concentrations and emissions of multiple pollutants from multiple spatial regions and economic sectors. In this study, we use the extended response surface modeling (ERSM) technique to investigate the nonlinear response of $\mathrm{PM}_{2.5}$ concentrations to emissions of multiple pollutants from different regions and sectors over the BTH region, based on over 1000 simulations by a chemical transport model (CTM). The ERSM-predicted $\mathrm{PM}_{2.5}$ concentrations agree well with independent CTM simulations, with correlation coefficients larger than 0.99 and mean normalized errors less than $1 \%$. Using the ERSM technique, we find that, among all air pollutants, primary inorganic $\mathrm{PM}_{2.5}$ makes the largest contribution (24-36\%) to $\mathrm{PM}_{2.5}$ concentrations. The contribution of primary inorganic $\mathrm{PM}_{2.5}$ emissions is especially high in heavily polluted winter and is dominated by the industry as well as residential and commercial sectors, which should be prioritized in $\mathrm{PM}_{2.5}$ control strategies. The to-
\end{abstract}

tal contributions of all precursors (nitrogen oxides, $\mathrm{NO}_{x}$; sulfur dioxides, $\mathrm{SO}_{2}$; ammonia, $\mathrm{NH}_{3}$; non-methane volatile organic compounds, NMVOCs; intermediate-volatility organic compounds, IVOCs; primary organic aerosol, POA) to $\mathrm{PM}_{2.5}$ concentrations range between 31 and $48 \%$. Among these precursors, $\mathrm{PM}_{2.5}$ concentrations are primarily sensitive to the emissions of $\mathrm{NH}_{3}, \mathrm{NMVOC}+\mathrm{IVOC}$, and POA. The sensitivities increase substantially for $\mathrm{NH}_{3}$ and $\mathrm{NO}_{x}$ and decrease slightly for POA and NMVOC + IVOC with the increase in the emission reduction ratio, which illustrates the nonlinear relationships between precursor emissions and $\mathrm{PM}_{2.5}$ concentrations. The contributions of primary inorganic $\mathrm{PM}_{2.5}$ emissions to $\mathrm{PM}_{2.5}$ concentrations are dominated by local emission sources, which account for over $75 \%$ of the total primary inorganic $\mathrm{PM}_{2.5}$ contributions. For precursors, however, emissions from other regions could play similar roles to local emission sources in the summer and over the northern part of BTH. The source contribution features for various types of heavy-pollution episodes are distinctly different from each other and from the monthly mean results, illustrating that control strategies should be differentiated based on the major contributing sources during different types of episodes. 


\section{Introduction}

China is one of the regions with the highest concentration of $\mathrm{PM}_{2.5}$ (particulate matter with aerodynamic diameter equal to or less than $2.5 \mu \mathrm{m}$ ) in the world (van Donkelaar et al., 2015). The problem is especially serious over the Beijing-Tianjin-Hebei (BTH) region, one of the most populous and developed regions in China. Annual average $\mathrm{PM}_{2.5}$ concentrations in this region reached $85-110 \mu \mathrm{g} \mathrm{m}^{-3}$ during 2013-2015, which approximately triple the standard threshold $\left(35 \mu \mathrm{g} \mathrm{m}^{-3}\right)$ and far exceed those in other metropolitan regions (Wang et al., 2017). It has been estimated that the severe $\mathrm{PM}_{2.5}$ pollution leads to about 1.05-1.23 million premature deaths per year in China (Lim et al., 2012; Burnett et al., 2014; J. D. Wang et al., 2016), and the monetized loss over the BTH region is as high as 134 billion Chinese Yuan, representing $2.2 \%$ of regional gross domestic product (GDP) ( $\mathrm{Lv}$ and $\mathrm{Li}, 2016$ ). Additionally, $\mathrm{PM}_{2.5}$ substantially affects global and regional climate by absorbing and scattering solar radiation and by altering cloud properties (IPCC, 2013; Seinfeld et al., 2016; Zhao et al., 2017a), which in turn exert an impact on regional air quality (J. D. Wang et al., 2014; Zhao et al., 2017b).

To tackle the heavy $\mathrm{PM}_{2.5}$ pollution problem, the Chinese government issued the Action Plan on Prevention and Control of Air Pollution in September 2013, which aimed at a $25 \%$ reduction in $\mathrm{PM}_{2.5}$ concentrations over the $\mathrm{BTH}$ region by 2017 from the 2012 levels (The State Council of the People's Republic of China, 2013). The attainment of an ambient $\mathrm{PM}_{2.5}$ standard would further require substantial reductions in air pollutant emissions (Wang et al., 2015, 2017). To establish emission control strategies, many studies have apportioned the sources of $\mathrm{PM}_{2.5}$ over the BTH region, either by mining monitoring data using the positive matrix factorization and chemical mass balance methods (e.g., Zhang et al., 2007; Yu et al., 2013) or by embedding chemical tracers in chemical transport models (CTMs) (e.g., Y. J. Wang et al., 2016; Li et al., 2015; Ying et al., 2014). While these studies can capture the current contributions of various sources to $\mathrm{PM}_{2.5}$ concentrations, these contributions could differ significantly from the $\mathrm{PM}_{2.5}$ reductions induced by reducing emissions from the corresponding sources, due to highly nonlinear chemical mechanisms (Han et al., 2016; Wang et al., 2011). Therefore, it is imperative to assess the nonlinear response of $\mathrm{PM}_{2.5}$ to pollutant emissions from multiple sources, which could provide direct support for the development of effective control policies.

The most widely used technique to evaluate the responses of $\mathrm{PM}_{2.5}$ concentrations to emission changes is the "brute force" method, which involves perturbing emissions from a certain source and repeating the solution of a CTM (Russell et al., 1995). A number of studies have utilized the brute force method to quantify the sensitivities of $\mathrm{PM}_{2.5}$ concentrations over the BTH region to emissions from different spatial regions (Streets et al., 2007; Wang et al., 2008; L. T. Wang et al., 2014; Li and Han, 2016) or different economic sectors (Wang et al., 2008; L. T. Wang et al. 2014; Han et al., 2016; Liu et al., 2016), either on a seasonal basis (Streets et al., 2007; Wang et al., 2008; Han et al., 2016; Liu et al., 2016) or during a specific heavy-pollution episode (Li and Han, 2016; L. T. Wang et al., 2014). To improve the computational efficiency, several mathematic techniques embedded in CTMs have been developed to simultaneously calculate the sensitivities of the modeled concentrations to multiple emission sources, including the decoupled direct method (Yang et al., 1997) and adjoint analysis (Sandu et al., 2005; Hakami et al., 2006). Zhang et al. (2016) used the adjoint analysis method to examine sensitivities of $\mathrm{PM}_{2.5}$ concentrations in the BTH region to pollutant emissions during several pollution periods. However, all the preceding studies only quantified firstorder sensitivities and therefore could not capture the nonlinearity in the responses of $\mathrm{PM}_{2.5}$ concentrations to pollutant emissions, which can be extremely strong in metropolitan regions like BTH due to complex chemical mechanisms (Wang et al., 2011). Moreover, no studies have simultaneously evaluated the response of $\mathrm{PM}_{2.5}$ concentrations in $\mathrm{BTH}$ to emissions of multiple pollutants from different sectors and regions, which we need to consider and balance to develop cost-effective control strategies.

In light of the drawbacks of the preceding methods, the response surface modeling (RSM) technique (denoted by "conventional RSM" hereafter to distinguish it from the extended response surface modeling, ERSM, technique) has been developed by using advanced statistical techniques to characterize the complex nonlinear relationship between model outputs and inputs (U.S. Environmental Protection Agency, 2006; Xing et al., 2011; Wang et al., 2011). This technique has been applied to the United States (U.S. Environmental Protection Agency, 2006) and eastern China (Wang et al., 2011) to evaluate the response of $\mathrm{PM}_{2.5}$ and its chemical components to pollutant emissions. However, the number of emission scenarios required to build conventional RSM depends on the variable number via an equation of fourth or higher order (Zhao et al., 2015b). Therefore, the required scenario number would be tens of thousands for over 15 variables and even hundreds of thousands for over 25 variables, which is computationally impossible for most threedimensional CTMs. To overcome this major limitation, we recently developed the ERSM technique (Zhao et al., 2015b), which substantially reduced the scenario number needed to build the response surface and hence extended its applicability to an increased number of regions, pollutants, and sectors with an acceptable computational burden.

Given the advantage of the ERSM technique, here we apply it to over 1000 simulations by the Community Multiscale Air Quality model with Two-Dimensional Volatility Basis Set (CMAQ/2D-VBS) to systematically evaluate the nonlinear response of $\mathrm{PM}_{2.5}$ to emission changes in multiple pollutants from different sectors and regions over the BTH region. The major sources contributing to $\mathrm{PM}_{2.5}$ and its ma- 
jor components are identified, and the nonlinearity in the response of $\mathrm{PM}_{2.5}$ to emission changes is characterized. Based on the results of this study, suggestions for $\mathrm{PM}_{2.5}$ control policies over the BTH region are proposed.

\section{Methodology}

\subsection{CMAQ/2D-VBS configuration and evaluation}

The CMAQ/2D-VBS model was developed in our previous study (Zhao et al., 2016) by incorporating the 2D-VBS model framework into CMAQv5.0.1. Compared with the default CMAQ, the CMAQ/2D-VBS model explicitly simulates aging of secondary organic aerosol (SOA) formed from non-methane volatile organic compounds (NMVOCs), aging of primary organic aerosol (POA), and photooxidation of intermediate-volatility organic compounds (IVOCs), thereby significantly improving the simulation results of organic aerosol (OA), particularly SOA. The model parameters within the 2D-VBS framework have been optimized in our previous studies (Zhao et al., 2015a, 2016) based on a series of smog-chamber experiments. Here we use the same model parameters as those of the "high-yield VBS" configuration reported in Zhao et al. (2016), which agrees best with surface OA and SOA observations among three model configurations. An application in eastern China reveals that CMAQ/2D-VBS reduces the underestimation in OA concentrations from $45 \%$ (default CMAQv5.0.1) to $19 \%$. More importantly, while the default CMAQv5.0.1 substantially underestimates the fraction of SOA in OA by 5-10 times and cannot track the oxygen-to-carbon ratio $(\mathrm{O}: \mathrm{C})$, the SOA fraction and $\mathrm{O}: \mathrm{C}$ simulated by $\mathrm{CMAQ} / 2 \mathrm{D}-\mathrm{VBS}$ agree fairly well with observations.

We apply the CMAQ/2D-VBS model over the BTH region. One-way, double-nesting simulation domains are used, as shown in Fig. 1. Domain 1 covers East Asia with a grid resolution of $36 \mathrm{~km} \times 36 \mathrm{~km}$; Domain 2 covers the $\mathrm{BTH}$ and its surrounding regions with a grid resolution of $12 \mathrm{~km} \times 12 \mathrm{~km}$. We use the SAPRC99 gas-phase chemistry module and the AERO6 aerosol module, in which the treatment of OA is replaced with the 2D-VBS framework. The aerosol thermodynamics is based on ISORROPIA-II. The initial and boundary conditions for Domain 1 are kept constant as the model default profile, and those for Domain 2 are extracted from the output of Domain 1. A 5-day spin-up period is used to reduce the influence of initial conditions on modeling results.

The Weather Research and Forecasting Model (WRF, version 3.7) is used to generate the meteorological fields. The National Center for Environmental Prediction (NCEP)'s FNL (Final) Operational Global Analysis data (ds083.2) at $1.0^{\circ} \times 1.0^{\circ}$ and $6 \mathrm{~h}$ resolution are used to generate the firstguess field. The NCEP's Automated Data Processing (ADP) data (ds351.0 and ds461.0) are used in objective analysis (i.e., grid nudging). The major physics options for WRF include the Kain-Fritsch cumulus scheme, the Pleim-Xiu land-surface module, the Asymmetric Convective Model with nonlocal upward mixing and local downward mixing (ACM2) for planetary boundary layer (PBL) parameterization, the Morrison double-moment scheme for cloud microphysics, and the Rapid Radiative Transfer Model for General Circulation Models (RRTMG) radiation scheme. The land cover type data are obtained from the Moderate resolution Imaging Spectroradiometer (MODIS). The simulation periods are January, March, July, and October in 2014, representing winter, spring, summer, and fall. We select these 4 months because the occurrence frequencies of various meteorological types in these months are statistically most similar to the average conditions in winter, spring, summer, and fall during 2004-2013 (Wu, 2016).

A high-resolution anthropogenic emission inventory in 2014 has been developed by Tsinghua University using an "emission factor method" (Fu et al., 2013; Zhao et al., 2013b) for the BTH region. The emissions from area and mobile sources are first calculated for each prefecture-level city based on statistical data and subsequently distributed into the model grids according to the spatial distribution of population, GDP, and road networks. A unit-based method (Zhao et al., 2008) is applied to estimate and locate the emissions from large point sources (LPSs) including power plants, iron and steel plants, and cement plants. The anthropogenic emission inventory in other provinces of China was originally developed for 2010 and 2012 in our previous studies (Zhao et al., 2013a, b; S. X. Wang et al., 2014; Cai et al., 2017); this has been updated to 2014 in this study following the same methodology. In both the BTH and national emission inventories, the emissions from the open burning of agricultural residue are calculated using crop yields, straw to grain ratio, fraction of biomass burned in the open field, and emission factors (Fu et al., 2013; Zhao et al., 2013b; Wang and Zhang, 2008). We do not include the emissions from forest and grassland fires, which typically account for less than $5 \%$ of the total biomass burning emissions over the BTH region (Qin and Xie, 2011) and are not the focus of the present study. Table S1 in the Supplement summarizes emissions of major air pollutants in each prefecture-level city over the $\mathrm{BTH}$ region in 2014; Table $\mathrm{S} 2$ gives the provincial emissions in the whole of China in 2014. The emissions for other countries are obtained from the MIX emission inventory ( $\mathrm{Li}$ et al., 2017) for 2010, which is the latest year available. Following our previous study (Zhao et al., 2016), we assume IVOC emissions to be 30 times, 4.5 times, 1.5 times, and 3.0 times the POA emissions from gasoline vehicles, diesel vehicles, biomass burning, and other emission sources, respectively, which is based on a series of laboratory measurements (Gordon et al., 2014a, b; Hennigan et al., 2011; Jathar et al., 2014). The biogenic emissions were calculated by the Model of Emissions of Gases and Aerosols from Nature (MEGAN; Guenther et al., 2006). 


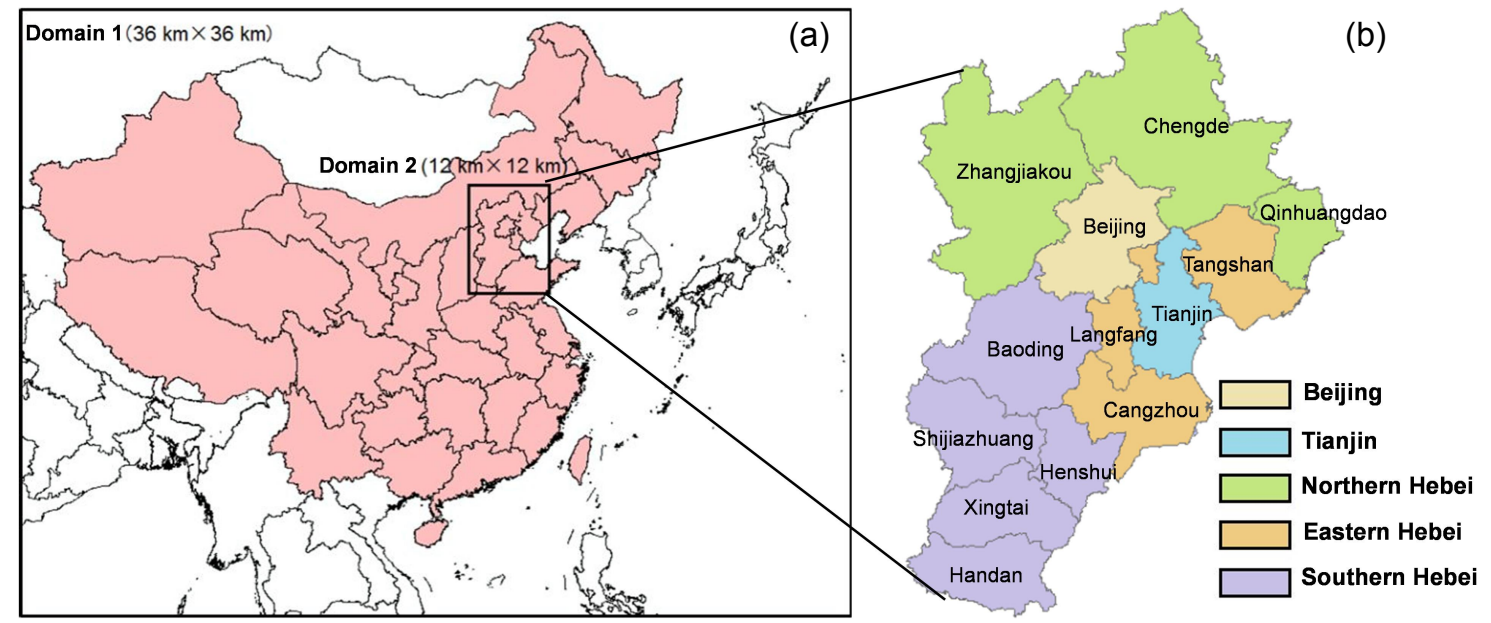

Figure 1. Double-nesting domains used in CMAQ/2D-VBS simulation (a) and the definition of five target regions in the innermost domain, denoted by different colors (b). The grey lines in (b) represent the boundaries of prefecture-level cities.

We compared the simulation results of WRFv3.7 and CMAQ/2D-VBS with meteorological observations obtained from the National Climatic Data Center (NCDC), $\mathrm{PM}_{2.5} \mathrm{ob}-$ servations at 138 state-controlled observational sites, and observations of major $\mathrm{PM}_{2.5}$ chemical components at seven sites within the modeling domain. We show that the meteorological and chemical simulations generally agree well with observations, with performance statistics mostly within the benchmark values proposed by previous studies. Details of the model evaluation methods and results are given in the Supplement (Sect. S1, Table S3-S5, Figs. S1-S5).

\subsection{Development of ERSM prediction system}

The detailed methodologies of the conventional RSM and ERSM techniques have been described in our previous papers (Zhao et al., 2015b; Xing et al., 2011). Here we only summarize some key components. The conventional RSM technique characterizes the relationships between a response variable (e.g., $\mathrm{PM}_{2.5}$ concentration) and a set of control variables (i.e., emissions of particular pollutants from particular sources) based on a number of randomly generated emission control scenarios (Xing et al., 2011; Wang et al., 2011). The $\mathrm{PM}_{2.5}$ concentration for each emission scenario is calculated with a CTM (CMAQ/2D-VBS in this study), and the conventional RSM is subsequently established using the maximumlikelihood estimation-empirical best linear unbiased predictors (MLE-EBLUPs) developed by Santner et al. (2003). Due to the limitation of the conventional RSM technique with respect to variable number, we have developed the ERSM technique (Zhao et al., 2015b) to extend the applicability to an increased number of variables and geographical regions. The ERSM technique first quantifies the relationship between $\mathrm{PM}_{2.5}$ concentrations and precursor emissions for each single region using the conventional RSM technique as described above and then assesses the effects of interregional transport of $\mathrm{PM}_{2.5}$ and its precursors on $\mathrm{PM}_{2.5}$ concentration in the target region. In order to quantify the interaction among regions, we introduce a key assumption that the emissions of precursors in the source region affect $\mathrm{PM}_{2.5}$ concentrations in the target region through two major processes: (1) the interregional transport of precursors enhancing the chemical formation of secondary $\mathrm{PM}_{2.5}$ in the target region; (2) the formation of secondary $\mathrm{PM}_{2.5}$ in the source region followed by transport to the target region. We quantify the individual contributions of these two processes as well as the contribution of local emissions in the target region, which are subsequently integrated to derive the total $\mathrm{PM}_{2.5}$ concentrations in the target region. The development of the ERSM prediction system requires several hundred to over 1000 emission scenarios, but once built, it enables realtime prediction of $\mathrm{PM}_{2.5}$ concentrations for any given control strategy and proves to be an efficient and user-friendly decision making tool. Moreover, ERSM can be applied to design a least-cost control strategy once it is coupled with control cost models/functions that links the emission reductions with economic costs.

For the application of the RSM/ERSM techniques to the BTH region, we define five target regions in the inner modeling domain (Domain 2), i.e., Beijing, Tianjin, Northern Hebei (N Hebei), Eastern Hebei (E Hebei), and Southern Hebei (S Hebei), as shown in Fig. 1. The decomposition of Hebei province is based on a preliminary analysis of the pollutant transport patterns over the BTH region (Sect. S2). The simulation using the back-trajectory method indicates that four major types of heavy-pollution episodes in Beijing are primarily contributed by air mass from the south, the local area, the northwest, and the southeast. We develop two RSM/ERSM prediction systems (Table 1). The response variables for the first prediction system, which is 
built using the conventional RSM technique, are concentrations of $\mathrm{PM}_{2.5}, \mathrm{SO}_{4}^{2-}, \mathrm{NO}_{3}^{-}$, and $\mathrm{OA}$ over the urban areas of prefecture-level cities in the five target regions. For the second prediction system that is established using the ERSM technique, the response variables are only $\mathrm{PM}_{2.5}$ concentrations. The first prediction system uses 101 emission control scenarios generated by the Latin hypercube sample (LHS) method (Iman et al., 1980) to map atmospheric concentrations versus emissions of five $\mathrm{PM}_{2.5}$ precursors, i.e., $\mathrm{NO}_{x}$, $\mathrm{SO}_{2}, \mathrm{NH}_{3}, \mathrm{NMVOC}+\mathrm{IVOC}$, and POA, in all five target regions (Table 1). It is on the one hand intended for the validation of the second system (Sect. 3.1) and, on the other hand, used to study the source contributions of major $\mathrm{PM}_{2.5}$ components. For the second system, the emissions of the preceding $\mathrm{PM}_{2.5}$ precursors as well as primary inorganic $\mathrm{PM}_{2.5}$ (i.e., the chemical components of primary $\mathrm{PM}_{2.5}$ other than POA) in each of the five regions are categorized into seven and four control variables, respectively, resulting in 55 control variables in total (Table 1). Note that we distinguish POA and primary inorganic $\mathrm{PM}_{2.5}$ because the former undergoes chemical reactions and produces SOA, while the latter is mostly chemically inert in the CMAQ/2D-VBS model. We generate 1121 scenarios (see Table 1) to build the response surface, following the method detailed in Zhao et al. (2015b). Specifically, the scenarios include (1) 1 CMAQ/2D-VBS base case; (2) 200 scenarios generated by applying the LHS method for the control variables of precursors in Beijing, $200 \times 4$ scenarios generated in the same way for Tianjin, Northern Hebei, Eastern Hebei, and Southern Hebei; (3) 100 scenarios generated by applying LHS method for the total emissions of $\mathrm{NO}_{x}, \mathrm{SO}_{2}, \mathrm{NH}_{3}, \mathrm{NMVOC}+\mathrm{IVOC}$, and POA in all five regions; and (4) 20 scenarios in which one of the control variables of primary inorganic $\mathrm{PM}_{2.5}$ emissions is set to 0.25 for each scenario. Here the scenario numbers (200 in group 2 and 100 in group 3) are determined based on numerical experiments conducted in our previous studies (Xing et al., 2011; Wang et al., 2011), which showed that the response surface for seven and five variables could be built with good prediction performance (mean normalized error < $1 \%$; correlation coefficient $>0.99$ ) using 200 and 100 scenarios, respectively. Finally, we generate 54 independent scenarios for out-of-sample validation, which will be detailed in Sect. 3.1.

For the application of the ERSM prediction system to quantitatively characterize the sensitivity of $\mathrm{PM}_{2.5}$ concentrations to emission changes, we define " $\mathrm{PM}_{2.5}$ sensitivity" as the change ratio of $\mathrm{PM}_{2.5}$ concentration divided by the reduction ratio of an emission source, following previous studies (Zhao et al., 2015b; Wang et al., 2011).

$S_{a}^{X}=\left[\left(C^{*}-C_{a}\right) / C^{*}\right] /(1-a)$,

where $S_{a}^{X}$ is the $\mathrm{PM}_{2.5}$ sensitivity to emission source $X$ at its emission ratio $a ; C^{*}$ and $C_{a}$ are $\mathrm{PM}_{2.5}$ concentrations in the base case (when the emission ratio of $X$ is 1) and in the control scenario, in which the emission ratio of $X$ is $a$, re- spectively. Similar indices can be defined for chemical components of $\mathrm{PM}_{2.5}$, such as $\mathrm{NO}_{3}^{-}, \mathrm{SO}_{4}^{2-}$, and $\mathrm{OA}$.

\section{Results and discussion}

\subsection{Validation of ERSM performance}

The conventional RSM technique has been extensively demonstrated to have high accuracy and stability in previous papers (Xing et al., 2011; Wang et al., 2011), so we only describe the validation of the ERSM technique. Following Zhao et al. (2015b), we assess the performance of the ERSM prediction system using the "out-of-sample" and 2D-isopleth validation methods, which focus on the accuracy and stability of the prediction system, respectively.

For out-of-sample validation, we use the ERSM prediction system to calculate the $\mathrm{PM}_{2.5}$ concentrations for 54 outof-sample control scenarios, i.e., scenarios independent from those used to build the prediction system, and compare them with the corresponding CMAQ/2D-VBS simulation results. These 54 out-of-sample scenarios (summarized in Table S6) include 40 cases (cases 1-40) in which the control variables of precursors change but those of primary inorganic $\mathrm{PM}_{2.5}$ stay the same as the base case, 4 cases (cases 41-44) that are the other way around, and 10 cases (cases 45-54) in which control variables of precursors and primary inorganic $\mathrm{PM}_{2.5}$ change simultaneously. Most cases are generated randomly with the LHS method (cases 4-6, 10-12, 16-18, 22-24, 28$54)$, and some cases are designed in which all control variables are subject to large emission changes (cases 1-3, 7-9, 13-15, 19-21, 25-27).

Figure 2 compares the ERSM-predicted and CMAQ/2DVBS-simulated $\mathrm{PM}_{2.5}$ concentrations and $\mathrm{PM}_{2.5}$ responses (defined as the difference between $\mathrm{PM}_{2.5}$ concentration in an emission control scenario and that in the base case) for the out-of-sample scenarios using scatterplots. Table 2 summarizes the statistics of the model performance. The definitions of normalized error (NE), mean normalized error (MNE), and normalized mean error (NME) are given as follows:

$$
\begin{aligned}
& \mathrm{NE}=\left|P_{i}-S_{i}\right| / S_{i}, \\
& \mathrm{MNE}=\frac{1}{N_{\mathrm{s}}} \sum_{i=1}^{N_{\mathrm{s}}}\left[\left|P_{i}-S_{i}\right| / S_{i}\right], \\
& \mathrm{NME}=\sum_{i=1}^{N_{\mathrm{s}}}\left|P_{i}-S_{i}\right| / \sum_{i=1}^{N_{\mathrm{s}}} S_{i},
\end{aligned}
$$

where $P_{i}$ and $S_{i}$ are the ERSM-predicted and CMAQ/2DVBS-simulated value of the $i$ th out-of-sample scenario; $N_{\mathrm{S}}$ is the number of out-of-sample scenarios. Figure 2 shows that the ERSM predictions and CMAQ/2D-VBS simulations agree well with each other. For $\mathrm{PM}_{2.5}$ concentrations, the correlation coefficients are larger than 0.99, and the MNEs and NMEs are less than $1 \%$ for all 4 months. The maximum NEs could be as large as $11 \%$ for a particular month and region, but the $95 \%$ percentiles of NEs are all within $4.4 \%$. 
Table 1. Description of the RSM/ERSM prediction systems developed in this study.

\begin{tabular}{|c|c|c|}
\hline Method & Control variables & Control scenarios \\
\hline Conventional RSM technique & $\begin{array}{l}\text { Five control variables: } \\
\text { total emissions of } \mathrm{NO}_{x}, \mathrm{SO}_{2}, \mathrm{NH}_{3}, \mathrm{NMVOC}+\mathrm{IVOC} \text {, and } \\
\text { POA. }\end{array}$ & $\begin{array}{l}\text { 101 control scenarios: } \\
\text { 1. } 1 \mathrm{CMAQ} / 2 \mathrm{D}-\mathrm{VBS} \text { base case, } \\
\text { 2. } 100^{\mathrm{a}} \text { scenarios generated by applying the LHS } \\
\text { method for the five variables. }\end{array}$ \\
\hline ERSM technique & $\begin{array}{l}55 \text { control variables in total: } \\
11 \text { control variables in each of the five regions, including } \\
\text { seven nonlinear control variables, i.e., } \\
\text { 1. } \mathrm{NO}_{x} / \text { large point sources (LPSs) } \\
\text { 2. } \mathrm{NO}_{x} \text { /other sources, } \\
\text { 3. } \mathrm{SO}_{2} / \text { LPS, } \\
\text { 4. } \mathrm{SO}_{2} \text { /other sources, } \\
\text { 5. } \mathrm{NH}_{3} / \text { all sources, } \\
\text { 6. NMVOC + IVOC/all sources, } \\
\text { 7. POA/all sources, } \\
\text { and four linear control variables, i.e., } \\
\text { 8. primary inorganic } \mathrm{PM}_{2.5} / \text { power plants, } \\
\text { 9. primary inorganic } \mathrm{PM}_{2.5} / \text { industry, } \\
\text { 10. primary inorganic } \mathrm{PM}_{2.5} / \text { residential and commercial, } \\
\text { 11. primary inorganic } \mathrm{PM}_{2.5} / \text { transportation. }\end{array}$ & $\begin{array}{l}\text { 1121 control scenarios: } \\
\text { 1. } 1 \mathrm{CMAQ} / 2 \mathrm{D}-\mathrm{VBS} \text { base case, } \\
\text { 2. } 1000 \text { scenarios, including } 200^{\mathrm{a}} \text { scenarios gen- } \\
\text { erated by applying LHS method for the nonlinear } \\
\text { control variables in Beijing, } 200 \text { scenarios gener- } \\
\text { ated in the same way for Tianjin, } 200 \text { scenarios } \\
\text { for Northern Hebei, } 200 \text { scenarios for Southern } \\
\text { Hebei, and } 200 \text { scenarios for Eastern Hebei, } \\
\text { 3. } 100^{\mathrm{a}} \text { scenarios generated by applying the LHS } \\
\text { method for the total emissions of } \mathrm{NO}_{x}, \mathrm{SO}_{2} \text {, } \\
\mathrm{NH}_{3} \text {, NMVOC + IVOC, and POA, } \\
\text { 4. } 20 \text { scenarios in which one primary inorganic } \\
\mathrm{PM}_{2.5} \text { control variable is set to } 0.25 \text { for each sce- } \\
\text { nario. }\end{array}$ \\
\hline
\end{tabular}

$\overline{\text { Overall, }}{ }^{\mathrm{a}} 100$ and 200 scenarios are needed for the response surfaces for five and seven variables, respectively (Xing et al., 2011; Wang et al., 2011). ${ }^{\mathrm{b}}$ LPS includes power plants, iron and steel plants, and cement plants.

NEs exceeding $4.4 \%$ happen only for the scenarios in which most control variables are reduced substantially, indicating relatively large errors at low emission rates, which is consistent with our previous study (Zhao et al., 2015b). Note that all sensitivity scenarios used in Sect. 3.2-3.4 have $\leq 80 \%$ emission reductions, which helps to avoid relatively large errors. We also examine the errors in predicted $\mathrm{PM}_{2.5}$ response. Since the CMAQ/2D-VBS-simulated $\mathrm{PM}_{2.5}$ responses are very close to zero in several scenarios, their normalized errors (NEs) and mean normalized errors (MNEs) could be extremely large even if the absolute errors are small, which cannot properly characterize the accuracy of the ERSM technique. For this reason, we only calculate the correlation coefficients and NMEs (Table 2). The correlation coefficients of the $\mathrm{PM}_{2.5}$ response are larger than 0.99, and the NMEs are within $5.6 \%$ for all months. In summary, the out-ofsample validation indicates an overall good agreement between ERSM predictions and CMAQ/2D-VBS simulations.

We further examine whether the ERSM technique can capture the trends in $\mathrm{PM}_{2.5}$ concentrations in response to continuous changes in precursor emissions, i.e., the stability of the ERSM technique. To this end, we compare the 2D isopleths of $\mathrm{PM}_{2.5}$ concentrations as a function of simultaneous changes in two precursors' emissions in all five regions derived from the ERSM and conventional RSM techniques. It should be noted that, although the ERSM technique is applicable to a much larger number of control variables than conventional RSM, the assumptions in the treatment of interregional transport (Sect. 2.2) in ERSM might affect its accuracy. Nevertheless, the predictions by conventional RSM can be regarded as proxies for real CMAQ/2D-VBS simula- tions since conventional RSM has been extensively demonstrated to have high accuracy and stability in previous studies (Xing et al., 2011; Wang et al., 2011). For this reason, the comparison between the ERSM and conventional RSM techniques helps to evaluate the stability of the ERSM technique. Figure 3 illustrates the $\mathrm{PM}_{2.5}$ isopleths in Beijing as a function of three combinations of precursors, i.e., $\mathrm{NO}_{x}$ and $\mathrm{NH}_{3}$, $\mathrm{SO}_{2}$ and $\mathrm{NH}_{3}$, and VOC + IVOC and POA; the isopleths for other regions are very similar and are thus not shown. The $x$ and $y$ axes of the figures represent the "emission ratio", defined as the ratios of the changed emissions to the emissions in the base case. For example, an emission ratio of 0.7 means the emission of a particular control variable accounts for $70 \%$ that of the base case. The color isopleths represent $\mathrm{PM}_{2.5}$ concentrations. The comparison shows that the shapes of isopleths derived from both prediction systems generally agree with each other. The agreement is very good for the case of VOC + IVOC and POA, and for the cases of $\mathrm{NO}_{x}$ and $\mathrm{NH}_{3}$ and $\mathrm{SO}_{2}$ and $\mathrm{NH}_{3}$ when the emission ratios for $\mathrm{NO}_{x}$ and $\mathrm{NH}_{3}$ are larger than 0.2. Relatively large errors occur at very low $\mathrm{NO}_{x} / \mathrm{NH}_{3}$ emission ratios $(<0.2)$ due primarily to an extremely strong nonlinearity. Within these low emission ranges, the ERSM technique can capture the general trends in $\mathrm{PM}_{2.5}$ concentrations in response to emission changes, but the concentration gradients predicted by ERSM are smaller than those given by conventional RSM. More studies are needed to further improve the performance of ERSM at very low $\mathrm{NO}_{x} / \mathrm{NH}_{3}$ emission ratios. Despite the existing errors, the general consistency between RSMand ERSM-predicted isopleths demonstrates the stability of the ERSM prediction system. In other words, the discrepan- 

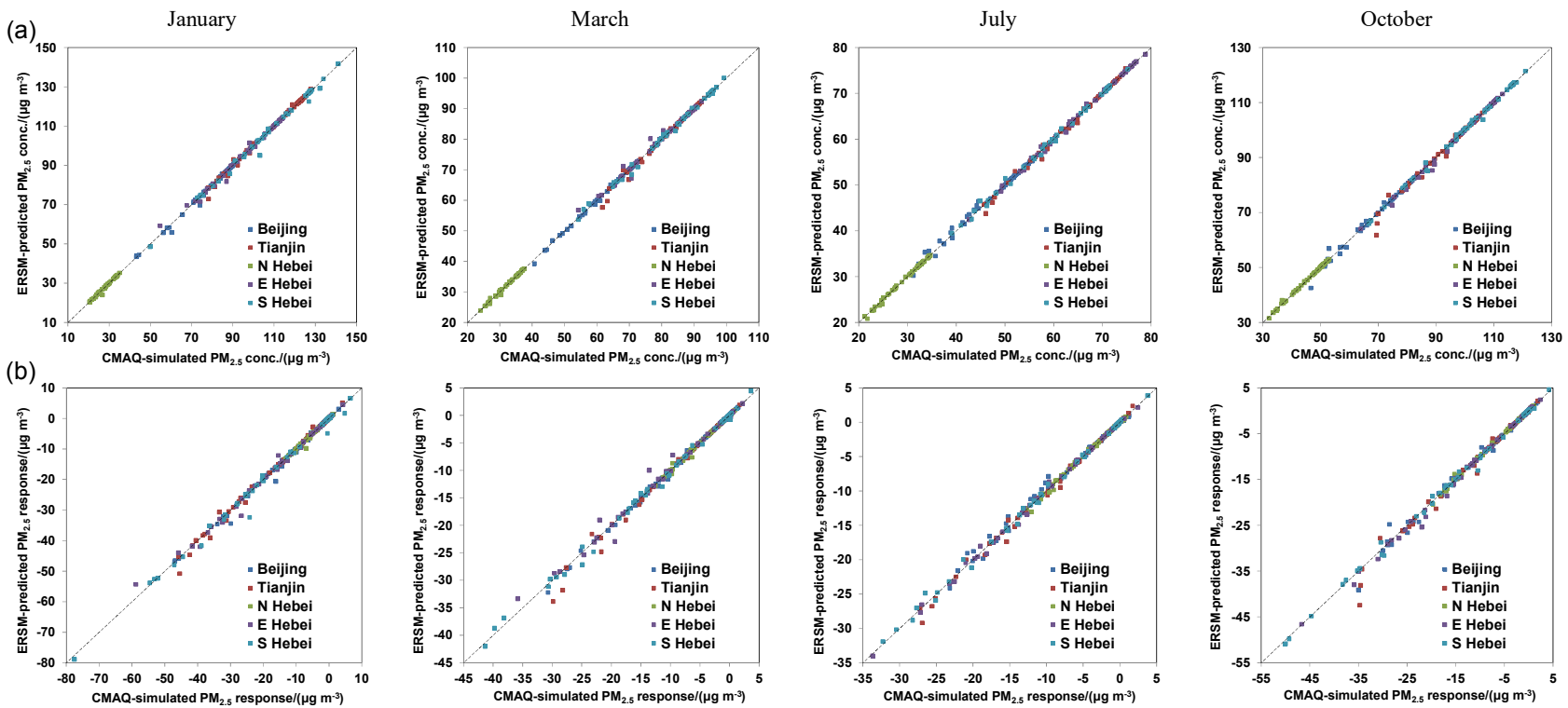

Figure 2. Comparison of $\mathrm{PM}_{2.5}$ concentrations (a) and $\mathrm{PM}_{2.5}$ responses (b) predicted by the ERSM technique with out-of-sample CMAQ/2D-VBS simulations. The dashed line is the one-to-one line, indicating perfect agreement.

Table 2. Comparison between ERSM-predicted and CMAQ/2D-VBS-simulated $\mathrm{PM}_{2.5}$ concentrations for 54 out-of-sample scenarios.

\begin{tabular}{|c|c|c|c|c|c|c|c|}
\hline Month & Variable & Statistical index & Beijing & Tianjin & Northern Hebei & Eastern Hebei & Southern Hebei \\
\hline \multirow[t]{7}{*}{ Jan } & \multirow{5}{*}{$\mathrm{PM}_{2.5}$ concentration } & $R$ & 0.998 & 0.998 & 0.995 & 0.997 & 0.997 \\
\hline & & $\operatorname{MNE}(\%)$ & 0.52 & 0.55 & 0.64 & 0.67 & 0.60 \\
\hline & & Maximum NE (\%) & 7.56 & 6.98 & 10.67 & 8.01 & 8.03 \\
\hline & & $95 \%$ percentile of NEs $(\%)$ & 1.61 & 2.86 & 2.92 & 3.46 & 3.02 \\
\hline & & $\operatorname{NME}(\%)$ & 0.44 & 0.46 & 0.57 & 0.53 & 0.53 \\
\hline & \multirow{2}{*}{$\mathrm{PM}_{2.5}$ response } & $R$ & 0.998 & 0.998 & 0.995 & 0.997 & 0.997 \\
\hline & & $\operatorname{NME}(\%)$ & 3.36 & 3.48 & 4.25 & 4.00 & 3.88 \\
\hline \multirow[t]{7}{*}{ Mar } & \multirow[t]{5}{*}{$\mathrm{PM}_{2.5}$ concentration } & $R$ & 0.999 & 0.996 & 0.998 & 0.995 & 0.999 \\
\hline & & $\operatorname{MNE}(\%)$ & 0.37 & 0.54 & 0.39 & 0.57 & 0.49 \\
\hline & & Maximum NE (\%) & 3.75 & 6.58 & 4.30 & 5.04 & 3.22 \\
\hline & & $95 \%$ percentile of NEs $(\%)$ & 1.53 & 3.15 & 2.03 & 4.35 & 2.03 \\
\hline & & $\operatorname{NME}(\%)$ & 0.31 & 0.45 & 0.34 & 0.49 & 0.42 \\
\hline & \multirow{2}{*}{$\mathrm{PM}_{2.5}$ response } & $R$ & 0.999 & 0.996 & 0.998 & 0.995 & 0.999 \\
\hline & & $\operatorname{NME}(\%)$ & 2.38 & 4.32 & 2.70 & 4.55 & 3.59 \\
\hline \multirow[t]{7}{*}{ Jul } & \multirow[t]{5}{*}{$\mathrm{PM}_{2.5}$ concentration } & $R$ & 0.997 & 0.998 & 0.998 & 0.999 & 0.999 \\
\hline & & $\operatorname{MNE}(\%)$ & 0.94 & 0.54 & 0.46 & 0.37 & 0.47 \\
\hline & & Maximum NE (\%) & 5.05 & 5.02 & 4.65 & 1.83 & 3.62 \\
\hline & & $95 \%$ percentile of NEs $(\%)$ & 3.47 & 2.33 & 2.17 & 1.49 & 1.87 \\
\hline & & $\operatorname{NME}(\%)$ & 0.80 & 0.47 & 0.41 & 0.33 & 0.39 \\
\hline & \multirow[t]{2}{*}{$\mathrm{PM}_{2.5}$ response } & $R$ & 0.997 & 0.998 & 0.998 & 0.999 & 0.999 \\
\hline & & $\operatorname{NME}(\%)$ & 4.97 & 3.71 & 2.80 & 2.58 & 2.78 \\
\hline \multirow[t]{7}{*}{ Oct } & \multirow[t]{5}{*}{$\mathrm{PM}_{2.5}$ concentration } & $R$ & 0.996 & 0.994 & 0.999 & 0.999 & 0.999 \\
\hline & & $\operatorname{MNE}(\%)$ & 0.83 & 0.70 & 0.36 & 0.39 & 0.36 \\
\hline & & Maximum NE (\%) & 8.90 & 11.19 & 3.79 & 3.90 & 2.46 \\
\hline & & $95 \%$ percentile of NEs $(\%)$ & 3.04 & 3.50 & 1.44 & 2.10 & 1.64 \\
\hline & & $\operatorname{NME}(\%)$ & 0.67 & 0.58 & 0.30 & 0.35 & 0.32 \\
\hline & \multirow[t]{2}{*}{$\mathrm{PM}_{2.5}$ response } & $R$ & 0.996 & 0.994 & 0.999 & 0.999 & 0.999 \\
\hline & & $\operatorname{NME}(\%)$ & 4.51 & 5.64 & 2.20 & 3.29 & 2.79 \\
\hline
\end{tabular}


cies between ERSM and CMAQ/2D-VBS cannot challenge the major conclusions on the effectiveness of emission reductions. Finally, as stated in the last paragraph, all sensitivity scenarios used in the following discussions have emission ratios $\geq 0.2$, since $<0.2$ emission reductions are quite rare as they are limited by the technologically feasible reduction potentials (S. X. Wang et al., 2014).

\subsection{Response of $\mathbf{P M}_{2.5}$ concentrations to emissions of air pollutants}

Having demonstrated the reliability of the ERSM prediction system, we employ it to investigate the responses of $\mathrm{PM}_{2.5}$ concentrations to emissions of various pollutants from different sectors and regions. We use $\mathrm{PM}_{2.5}$ sensitivity defined in Sect. 2.2 to quantitatively characterize the sensitivity of $\mathrm{PM}_{2.5}$ concentrations to emission changes. Figure 4 illustrates the sensitivity of 4-month (January, March, July, and October) mean $\mathrm{PM}_{2.5}$ concentrations to the stepped control of individual air pollutants (a) and individual pollutantsector combinations (b) in the BTH region, which are derived from the ERSM technique. The Fig. 4a can be obtained from both the RSM and ERSM prediction systems, and their results are consistent, whereas Fig. 4b, as well as the results shown in Figs. 5 and 6 can only be derived from ERSM. Among all pollutants, the 4-month mean $\mathrm{PM}_{2.5}$ concentrations are the most sensitive to the emissions of primary inorganic $\mathrm{PM}_{2.5}$ in all five regions, and the $\mathrm{PM}_{2.5}$ sensitivities vary from 24 to $36 \%$ according to region. When primary inorganic $\mathrm{PM}_{2.5}$ emissions from various sectors are differentiated, the industry sector is found to make the largest contribution to $\mathrm{PM}_{2.5}$ concentrations, followed by the residential and commercial sectors; the contribution of power plants is negligibly small because of smaller emissions and higher stacks. The $\mathrm{PM}_{2.5}$ sensitivities to primarily inorganic $\mathrm{PM}_{2.5}$ emissions remain constant at various reduction ratios.

While primary inorganic $\mathrm{PM}_{2.5}$ makes the largest contribution to $\mathrm{PM}_{2.5}$ concentrations among all air pollutants, the total contributions of all precursors $\left(\mathrm{NO}_{x}, \mathrm{SO}_{2}, \mathrm{NH}_{3}\right.$, NMVOC, IVOC, and POA), which range between 31 and $48 \%$, exceed that of primary inorganic $\mathrm{PM}_{2.5}(24-36 \%)$. Among the precursors, $\mathrm{PM}_{2.5}$ concentrations are primarily sensitive to the emissions of $\mathrm{NH}_{3}, \mathrm{NMVOC}+\mathrm{IVOC}$, and POA, and their relative importance differs according to reduction ratio. The $\mathrm{PM}_{2.5}$ sensitivity to $\mathrm{NH}_{3}$ increases substantially with the increase in reduction ratio, primarily attributable to the transition from $\mathrm{NH}_{3}$-rich to $\mathrm{NH}_{3}$-poor regimes when more controls are enforced. The $\mathrm{PM}_{2.5}$ sensitivities to POA and NMVOC + IVOC, however, decrease slightly with the increase in reduction ratio. This is because, based on the gas-particle absorptive partitioning theory, organics have a higher tendency to partition into the particle phase at larger OA concentrations. As a result of the nonlinearity, the $\mathrm{PM}_{2.5}$ sensitivities to POA and NMVOC + IVOC emissions are larger than those to $\mathrm{NH}_{3}$ emissions at small re- duction ratios (e.g., $20 \%$ ), while it is the other way around at large reduction ratios (e.g., $80 \%$ ).

The $\mathrm{PM}_{2.5}$ sensitivity to $\mathrm{SO}_{2}$ emissions is considerably smaller compared with the three precursors above and does not change significantly as a function of reduction ratio. From 2007 to 2014 (the base year of this study), both $\mathrm{SO}_{2}$ emissions and $\mathrm{SO}_{4}^{2-}$ concentrations in $\mathrm{PM}_{2.5}$ have been continuously decreasing due to effective control policies (Wang et al., 2017), which partly explains the small sensitivity of $\mathrm{PM}_{2.5}$ to $\mathrm{SO}_{2}$ emissions. The response of $\mathrm{PM}_{2.5}$ concentrations to $\mathrm{NO}_{x}$ emissions could change from negative to positive with the increase in reduction ratio, which has been reported in several previous studies (Dong et al., 2014; Zhao et al., 2013c; Cai et al., 2017). Small $\mathrm{NO}_{x}$ emission reductions could lead to an increase in $\mathrm{O}_{3}$ and $\mathrm{HO}_{x}$ concentrations in several seasons owing to an NMVOC-limited photochemical regime, which on the one hand enhances $\mathrm{SO}_{4}^{2-}$ and $\mathrm{SOA}$ formation and, on the other hand, could also increase $\mathrm{NO}_{3}^{-}$concentrations by accelerating the nocturnal formation of $\mathrm{N}_{2} \mathrm{O}_{5}$ and $\mathrm{HNO}_{3}$ through the $\mathrm{NO}_{2}+\mathrm{O}_{3}$ reaction at low temperatures. A substantial reduction in $\mathrm{NO}_{x}$ emissions, however, transforms the NMVOC-limited regime to an $\mathrm{NO}_{x}$-limited regime, resulting in a successive decline in concentrations of $\mathrm{O}_{3}, \mathrm{HO}_{x}$, and most $\mathrm{PM}_{2.5}$ chemical components. Judging from our simulation results (Fig. 4), if only the $\mathrm{NO}_{x}$ emissions within the BTH region are controlled, a very large reduction ratio of about $80 \%$ is required to realize a reduction in annual $\mathrm{PM}_{2.5}$ concentrations in most areas. However, the effects could be distinctly different if $\mathrm{NO}_{x}$ emissions outside the BTH region are jointly reduced. Our previous studies using the CMAQ model (Zhao et al., 2013c; Wang et al., 2010, 2011) have shown that uniform reductions in $\mathrm{NO}_{x}$ emissions in the whole of China by 23-50\% result in considerable annual $\mathrm{PM}_{2.5}$ reduction over the $\mathrm{BTH}$ region. This is because $\mathrm{NO}_{x}$ emission reductions in upwind regions are more likely to result in a net $\mathrm{PM}_{2.5}$ decrease compared with local emission reductions, since the photochemistry typically changes from an NMVOC-limited regime in local urban areas at the surface to an $\mathrm{NO}_{x}$-limited regime in downwind areas or at upper levels (Xing et al., 2011). The results shown in Fig. 4 also support the abovementioned pattern and mechanism to some extent: even a $20 \% \mathrm{NO}_{x}$ emission reduction in $\mathrm{BTH}$ can lead to $\mathrm{PM}_{2.5}$ decrease in Northern Hebei because, as the northernmost region in BTH, it is significantly affected by emissions in other regions within BTH. Note that some recently discovered chemical pathways are missing in the model, such as the oxidation of $\mathrm{SO}_{2}$ by $\mathrm{NO}_{2}$ in aerosol water and the $\mathrm{SO}_{2}$ heterogeneous reactions on the dust surface $(\mathrm{Fu}$ et al., 2016; Cheng et al., 2016; G. H. Wang et al., 2016). The incorporation of these processes in the model may affect the simulated responses of $\mathrm{PM}_{2.5}$ to $\mathrm{NO}_{x}$ and $\mathrm{SO}_{2}$ emissions. Regarding emission sectors, the contributions of $\mathrm{SO}_{2}$ and $\mathrm{NO}_{x}$ emissions are dominated by "other sources" (sources other than LPS) because they emit larger amount of pollutants at lower height compared with LPS. 


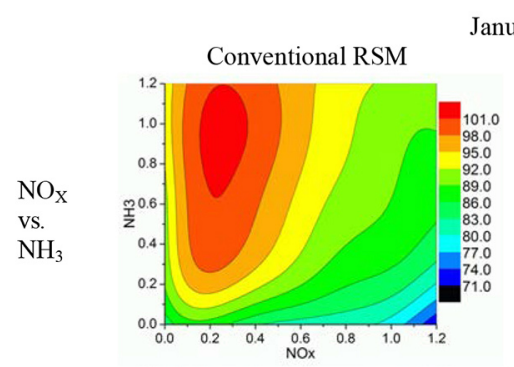

January
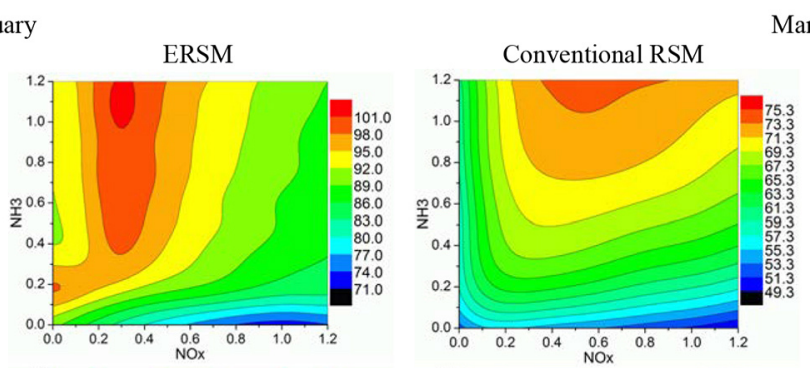

March
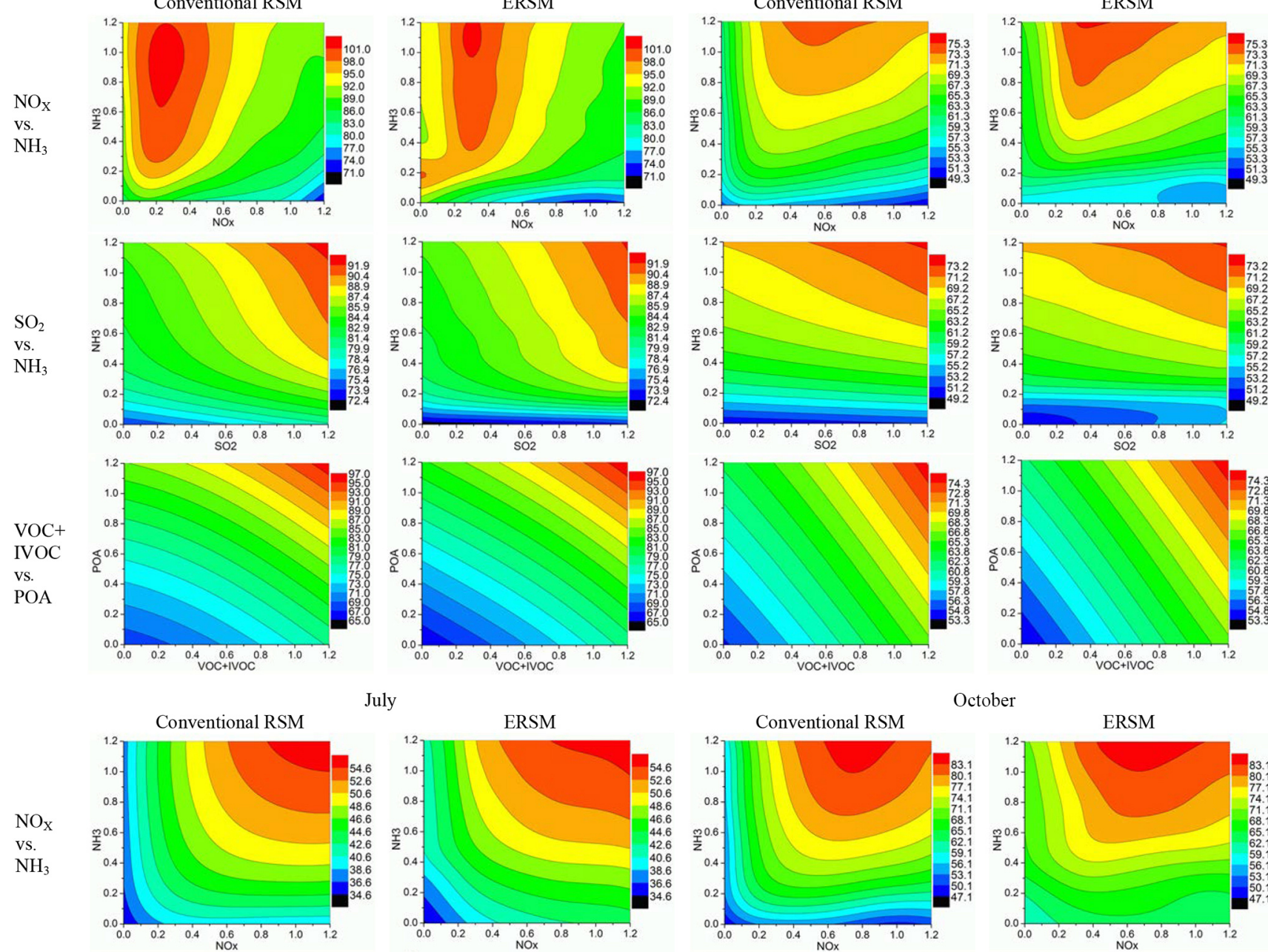

July
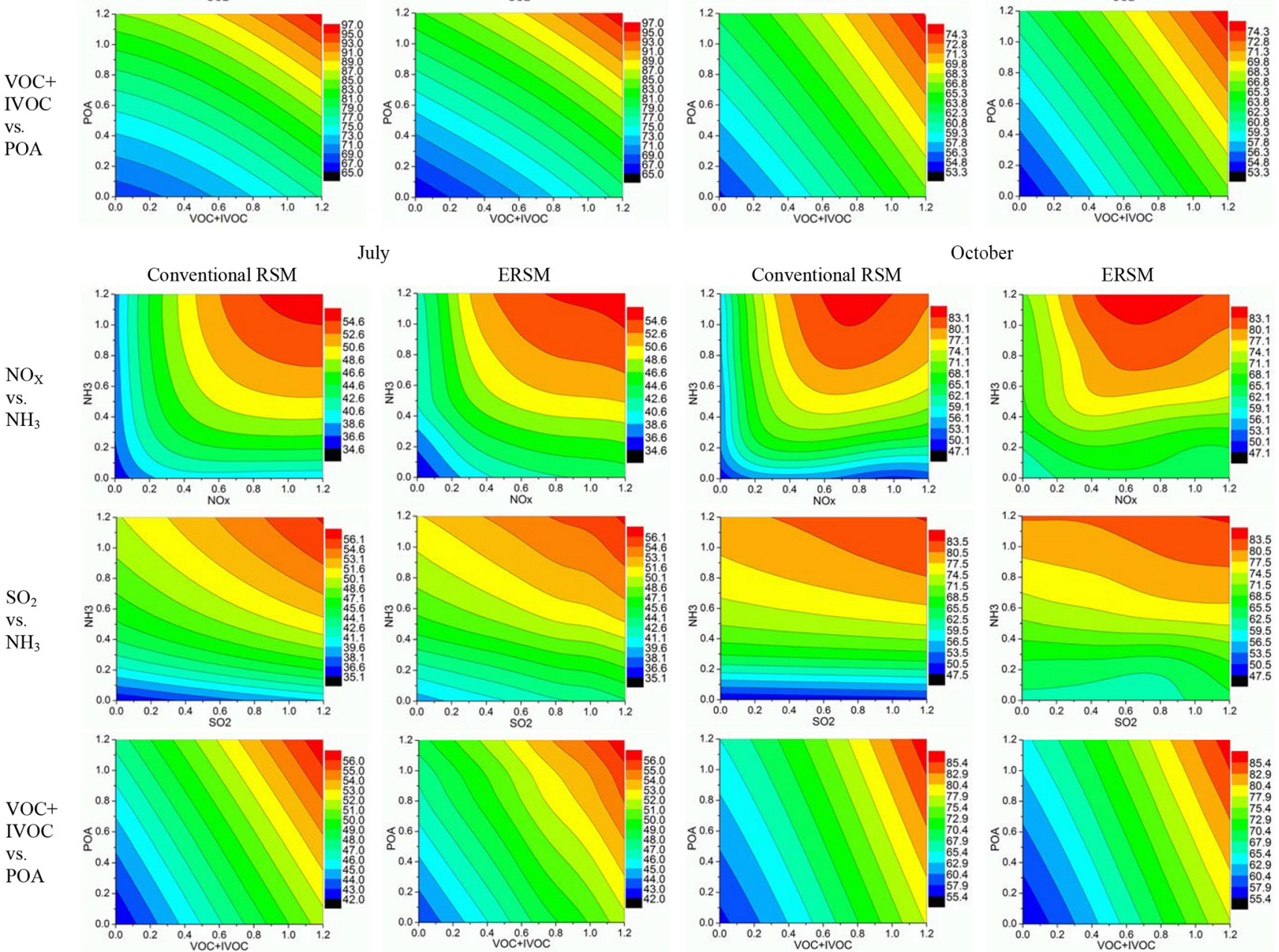

Figure 3. Comparison of the 2-D isopleths of $\mathrm{PM}_{2.5}$ concentrations in Beijing in response to the simultaneous changes in precursor emissions in all five regions derived from the conventional RSM technique and the ERSM technique. The $x$ and $y$ axes represent the emission ratio, defined as the ratios of the changed emissions to the emissions in the base case. The color contours represent $\mathrm{PM}_{2.5}$ concentrations (unit: $\left.\mu \mathrm{g} \mathrm{m}^{-3}\right)$. 

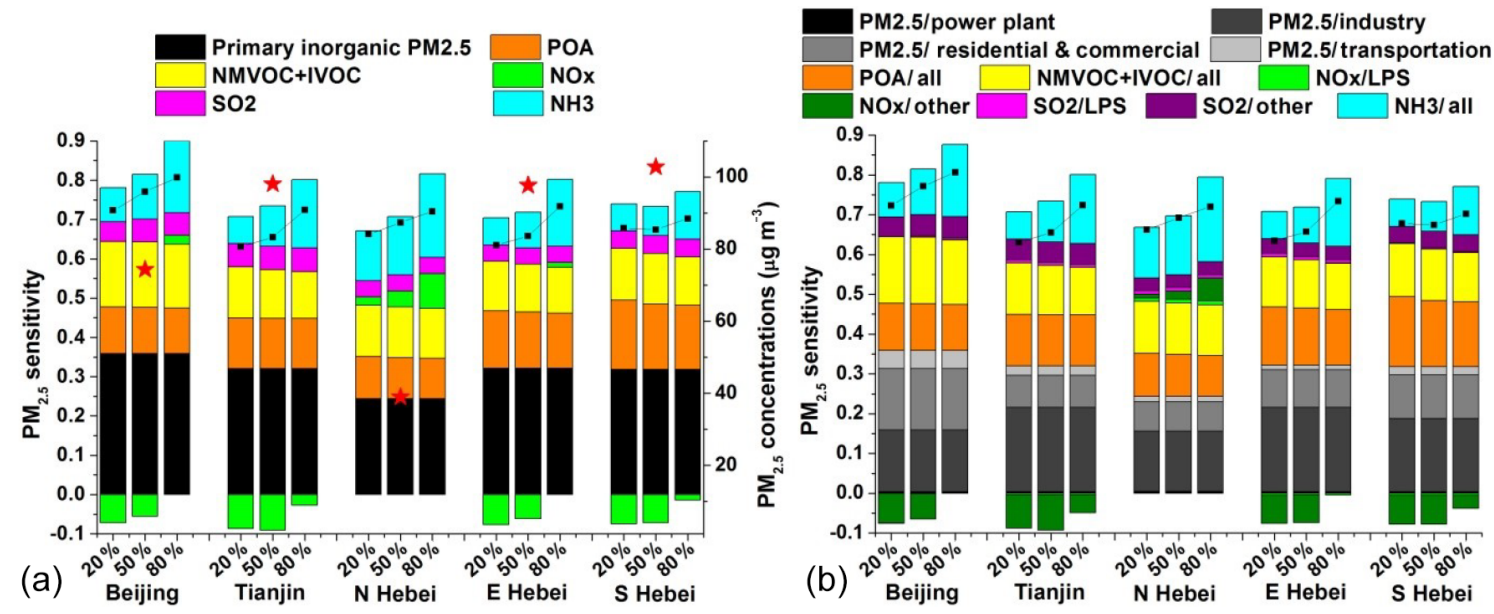

Figure 4. Sensitivity of 4-month mean $\mathrm{PM}_{2.5}$ concentrations to the stepped control of individual air pollutants (a) and individual pollutantsector combinations (b). The $x$ axis shows the reduction ratio $\left(1-\right.$ emission ratio). The $y$ axis shows $\mathrm{PM}_{2.5}$ sensitivity, which is defined as the change ratio of concentration divided by the reduction ratio of emissions. The colored bars denote the $\mathrm{PM}_{2.5}$ sensitivities when a particular emission source is controlled while the others stay the same as the base case; the black dotted line denotes the PM 2.5 sensitivity when all emission sources are controlled simultaneously. The red stars represent $\mathrm{PM}_{2.5}$ concentrations in the base case.

The black dotted lines in Fig. 4 show the $\mathrm{PM}_{2.5}$ sensitivity when all pollutants from all sectors are controlled simultaneously. The sum of $\mathrm{PM}_{2.5}$ sensitivities to individual pollutant-sector combinations (stacked columns) is mostly larger than the sensitivity to all pollutants and sectors (black dotted lines), especially under large reduction ratios. This is mainly attributed to the overlapping effect of two precursors (e.g., $\mathrm{SO}_{2}$ and $\mathrm{NH}_{3}$ ) involved in the formation of ammonium sulfate and ammonium nitrate. Nevertheless, at small reduction ratios, the sum of individual sensitivities is sometimes smaller because the negative effects of reducing $\mathrm{NO}_{x}$ are mitigated when we simultaneously reduce $\mathrm{NO}_{x}$ emissions from multiple sectors as well as emissions of other air pollutants such as NMVOC. When all pollutants and sectors are controlled together, the $\mathrm{PM}_{2.5}$ sensitivity generally increases with reduction ratio, indicating that an additional air quality benefit could be achieved, larger than expected from linear extrapolation, if more control measures were implemented.

Figure 5 illustrates the $\mathrm{PM}_{2.5}$ sensitivities to individual pollutant-sector combinations in each month. The source contribution features are significantly discrepant in different months. The contributions of primary inorganic $\mathrm{PM}_{2.5}$ emissions to $\mathrm{PM}_{2.5}$ concentrations are notably higher in January than in other months, which is probably attributed to weaker dilution and slower chemical reactions in January. Regarding different emission sectors of primary inorganic $\mathrm{PM}_{2.5}$, the industrial sector plays a dominant role in all months except January, when the residential and commercial sectors make a similar or even larger contribution as compared to the industrial sector. The higher contribution of the residential and commercial sectors in January is on the one hand because of the higher emissions due to heating, and, on the other hand, it is explained by weaker vertical mixing in winter, which results in a larger relative contribution of low-level sources. This result highlights the importance of residential and commercial sources for $\mathrm{PM}_{2.5}$ pollution controls in the winter. The contributions of precursors are dominated by POA and NMVOC + IVOC in January, while in July, $\mathrm{NO}_{x}, \mathrm{SO}_{2}$, and $\mathrm{NH}_{3}$, which are known to be precursors of secondary inorganic aerosols, make larger contributions than POA and NMVOC + IVOC. The responses of $\mathrm{PM}_{2.5}$ concentrations to $\mathrm{NO}_{x}$ emissions can be the opposite in different seasons. Specifically, in July, $\mathrm{NO}_{x}$ emission reductions always induce a decrease in $\mathrm{PM}_{2.5}$ concentrations due to an $\mathrm{NO}_{x}$-limited photochemical regime. In January, however, even an $80 \%$ reduction in $\mathrm{NO}_{x}$ emissions (roughly the maximum technically feasible reduction ratio) could result in a net $\mathrm{PM}_{2.5}$ increase, as a result of a strong NMVOC-limited regime. To achieve a net $\mathrm{PM}_{2.5}$ reduction in January, it would be necessary to simultaneously reduce $\mathrm{NO}_{x}$ emissions outside the BTH region.

We further evaluate the contributions of primary inorganic $\mathrm{PM}_{2.5}$ and precursor emissions from various regions to $\mathrm{PM}_{2.5}$ concentrations (Figs. 6 and S6). Here the contributions are quantified by comparing the base case with sensitivity scenarios in which emissions from a specific source are reduced by $80 \%$, which reaches the maximum technologically feasible reduction ratios of major pollutants in most areas (S. X. Wang et al., 2014). Obviously, the contributions of total primary inorganic $\mathrm{PM}_{2.5}$ emissions in the $\mathrm{BTH}$ region are dominated by local sources, which account for over $75 \%$ of the total primary inorganic $\mathrm{PM}_{2.5}$ contributions. When precursor emissions are decomposed into different regions, local sources usually also represent the largest contributors, but precursor emissions from other regions (denoted by "regional precursor emissions" hereafter) could also make significant 


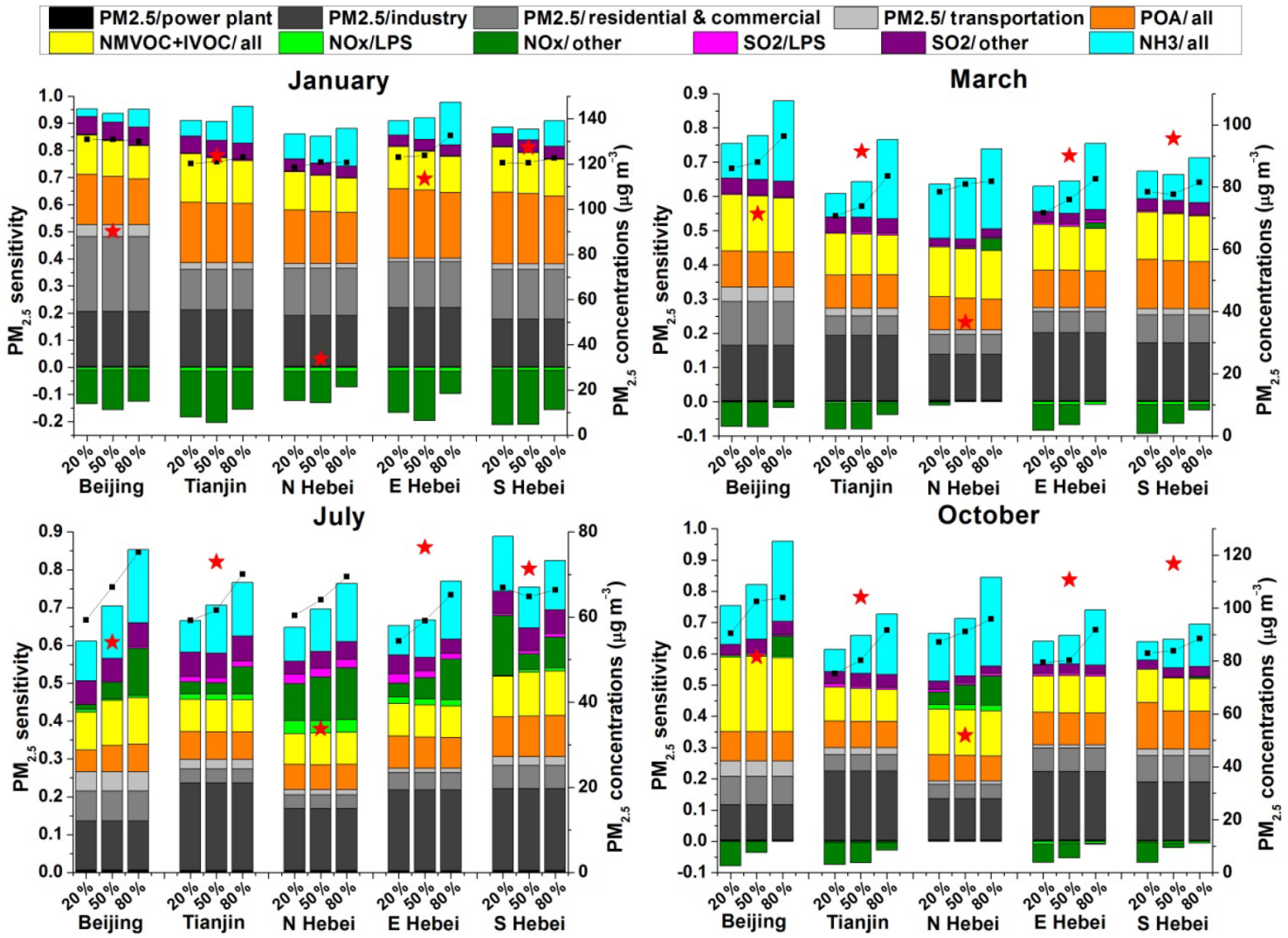

Figure 5. Sensitivity of monthly mean $\mathrm{PM}_{2.5}$ concentrations to the stepped control of individual air pollutants from individual sectors in January, March, July, and October. The meanings of $x$ axis, $y$ axis, colored bars, black dotted lines, and red stars are the same as in Fig. 4 .

contributions, depending on regions and seasons. The precursor emissions from the northern part of BTH (e.g., Northern Hebei, Beijing) mainly contribute to local $\mathrm{PM}_{2.5}$ concentrations, whereas those from the southern part of BTH (e.g., Southern Hebei) significantly affect the $\mathrm{PM}_{2.5}$ concentrations in both the local region and other regions. Over the $\mathrm{BTH}$, heavy pollution is frequently associated with southerly wind, while strong northerly wind often blows away $\mathrm{PM}_{2.5}$ pollution (Jia et al., 2008; Zheng et al., 2015), which explains the higher contribution of emissions from southern BTH to other regions. Moreover, the importance of regional precursor emissions relative to local ones is remarkably higher in July than in January, which can be explained by the southerly monsoon and stronger vertical mixing in summer that favors the interregional transport of air pollutants. We also examine the contributions of emissions outside the BTH region to $\mathrm{PM}_{2.5}$ concentrations in the five target regions. The results reveal that these emissions contribute $24-33 \%$ of the 4month mean $\mathrm{PM}_{2.5}$ concentrations, among which more than $80 \%$ could be attributed to precursor emissions. Among the 4 months, the contribution of emissions outside BTH is considerably smaller in January (12-21\%) as compared to other months (29-38\%).

\subsection{Response of $\mathbf{P M}_{2.5}$ chemical components to emissions of air pollutants}

Ambient $\mathrm{PM}_{2.5}$ is comprised of complicated chemical components with distinctly different formation pathways. To gain deeper insight into the formation mechanisms and source attribution of $\mathrm{PM}_{2.5}$, we examine the sensitivities of major $\mathrm{PM}_{2.5}$ components, including $\mathrm{NO}_{3}^{-}, \mathrm{SO}_{4}^{2-}$, and $\mathrm{OA}$, to the stepped control of individual air pollutants, as shown in Fig. 7 (January and July) and Fig. S7 (March and October). $\mathrm{NO}_{3}^{-}$ concentrations are the most sensitive to $\mathrm{NH}_{3}$ emissions in all months except July, when the sensitivities of $\mathrm{NO}_{3}^{-}$concentrations to $\mathrm{NH}_{3}$ and $\mathrm{NO}_{x}$ emissions are similar. The $\mathrm{NO}_{3}^{-}$ sensitivities to $\mathrm{NO}_{x}$ emissions differ significantly according to season. In most months, $\mathrm{NO}_{3}^{-}$concentrations are positively correlated with $\mathrm{NO}_{x}$ emissions. In January, however, the sensitivities of $\mathrm{NO}_{3}^{-}$concentrations to $\mathrm{NO}_{x}$ emissions are mostly negative and could be positive at large reduction ratios, which can be explained by a very strong NMVOClimited photochemical regime and abundant ice water for the heterogeneous formation of $\mathrm{HNO}_{3}$ from $\mathrm{N}_{2} \mathrm{O}_{5}$ at cold temperatures. The sensitivities of $\mathrm{NO}_{3}^{-}$to both $\mathrm{NH}_{3}$ and $\mathrm{NO}_{x}$ emissions show pronounced increasing trends with the increase in reduction ratio, in agreement with the strong 


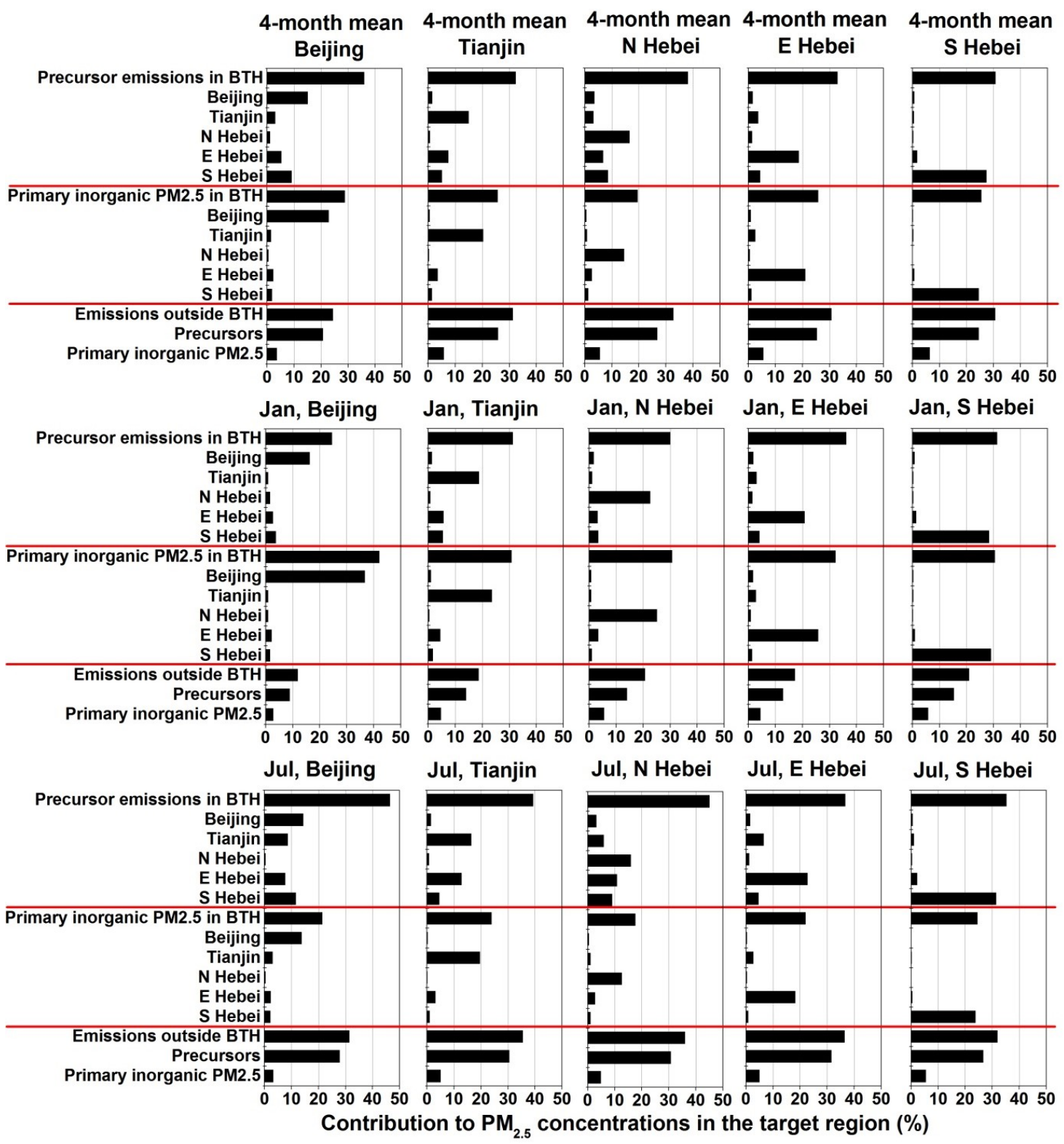

Figure 6. Contributions of precursor $\left(\mathrm{NO}_{x}, \mathrm{SO}_{2}, \mathrm{NH}_{3}, \mathrm{NMVOC}\right.$, IVOC, and POA) and primary inorganic $\mathrm{PM}_{2.5}$ emissions from individual regions to $\mathrm{PM}_{2.5}$ concentrations. The contributions are quantified by comparing the base case with sensitivity scenarios in which emissions from a specific source are reduced by $80 \%$. This figure illustrates contributions to 4-month mean $\mathrm{PM}_{2.5}$ concentrations and monthly mean $\mathrm{PM}_{2.5}$ concentrations in January and July. The results for March and October are given in Fig. S6.

nonlinearity in these two pollutants described in Sect. 3.2. NMVOC emissions make moderate positive contributions to $\mathrm{NO}_{3}^{-}$, with the largest and smallest contributions occurring in January and July in conjunction with NMVOC-limited and $\mathrm{NO}_{x}$-limited photochemical regimes, respectively. Finally, $\mathrm{SO}_{2}$ emissions have very small influences on $\mathrm{NO}_{3}^{-}$concentrations.

For $\mathrm{SO}_{4}^{2-}, \mathrm{SO}_{2}$ emissions represent the dominant contributor in all months. The sensitivity of $\mathrm{SO}_{4}^{2-}$ concentrations to $\mathrm{SO}_{2}$ emissions does not change significantly with respect to reduction ratio, consistent with the results shown in Section 3.2. The contributions of $\mathrm{NH}_{3}$ emissions to $\mathrm{SO}_{4}^{2-}$ concentrations are quite small except in October, when $\mathrm{NH}_{3}$ accounts for approximately one-fourth of the contribution of $\mathrm{SO}_{2} . \mathrm{NO}_{x}$ emissions affect $\mathrm{SO}_{4}^{2-}$ concentrations mainly by altering $\mathrm{O}_{3}$ and $\mathrm{HO}_{x}$ concentrations, the effects of which are positive in July at large reduction ratios and mostly negative in other months. NMVOC emissions can make a small impact on $\mathrm{SO}_{4}^{2-}$ concentrations primarily through changing $\mathrm{O}_{3}$ and $\mathrm{HO}_{x}$ concentrations. 


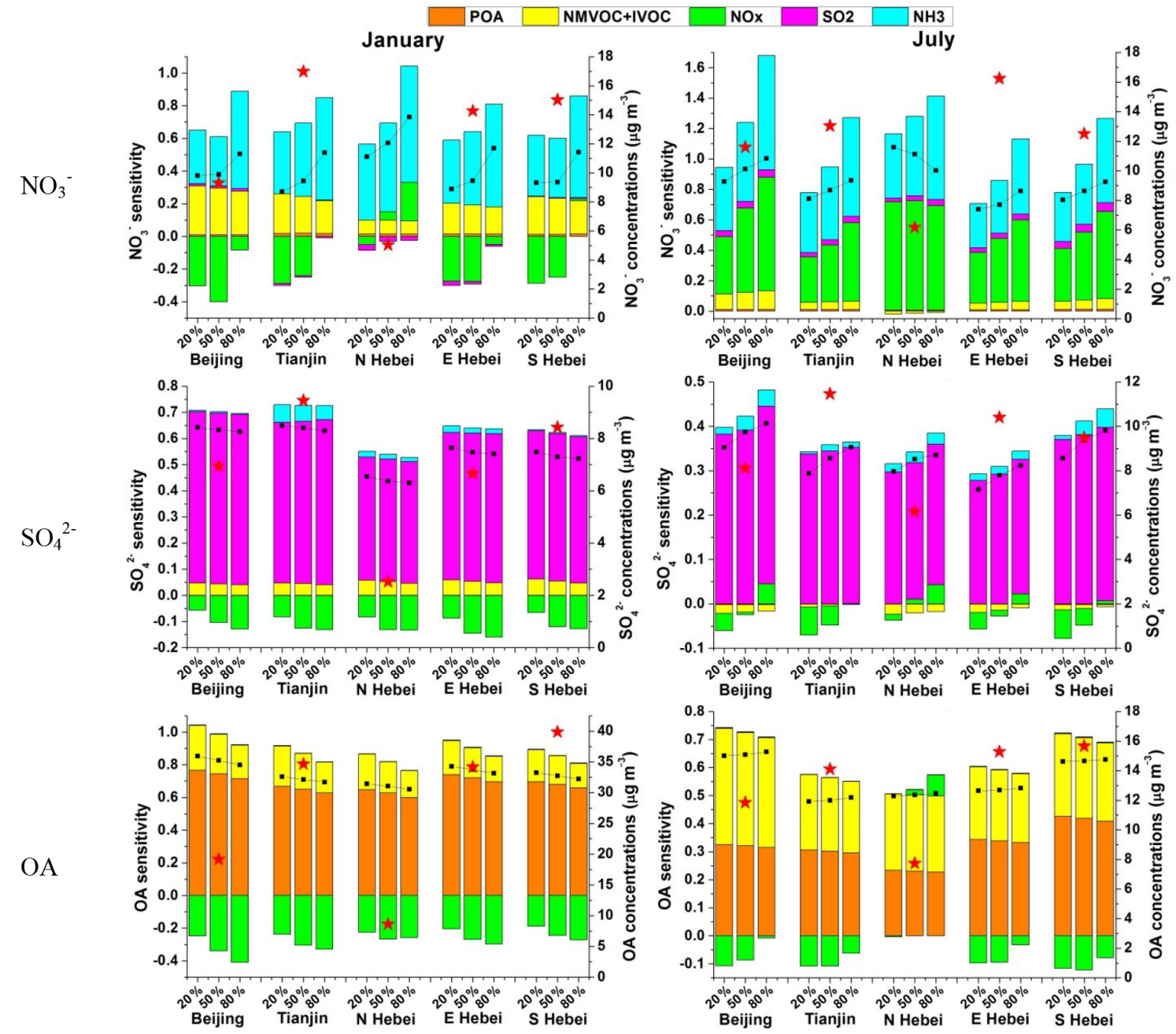

Figure 7. Sensitivity of monthly mean $\mathrm{NO}_{3}^{-}, \mathrm{SO}_{4}^{2-}$, and OA concentrations to the stepped control of individual air pollutants in January and July. The meanings of $x$ axis, $y$ axis, colored bars, black dotted lines, and red stars are the same as in Fig. 4 but for $\mathrm{NO}_{3}^{-} / \mathrm{SO}_{4}^{2-} / \mathrm{OA}^{\text {. The }}$ results for March and October are given in Fig. S7.

The emissions of POA and NMVOC + IVOC are obviously two major contributors to OA concentrations. The relative importance of the two is strongly dependent on season. In July, POA and NMVOC + IVOC make similar contributions to OA concentrations, while POA usually contributes more in other months. In January, the contribution of POA could account for about 4 times that of NMVOC + IVOC. The higher relative contribution of POA emissions in January can be explained in several ways. First, the POA emissions are relatively higher in January due to residential heating, while the NMVOC emissions from solvent use and biogenic sources are higher in July. Second, lower temperature in winter favors the partitioning of the semi-volatile components comprising POA to the particle phase, whereas higher temperature and stronger radiation in July accelerate the formation of SOA from NMVOC + IVOC. Similar to $\mathrm{SO}_{4}^{2-}$, the impact of $\mathrm{NO}_{x}$ emissions on OA concentrations also works through two pathways. Besides the abovementioned photochemical pathway, $\mathrm{NO}_{x}$ emission reductions could lead to $\mathrm{OA}$ increases due to the fact that SOA yield, defined as the ratio of SOA formation to the consumption of a precursor, is generally higher at a low- $\mathrm{NO}_{x}$ condition than at a high- $\mathrm{NO}_{x}$ condition. As an integrated effect, the responses of OA concentrations to $\mathrm{NO}_{x}$ emissions are negative in most situations.

\section{4 $\mathrm{PM}_{2.5}$ responses to emission reductions during heavy-pollution episodes}

Having shown the responses of monthly mean $\mathrm{PM}_{2.5}$ concentrations to pollutant emissions, we are also interested in heavy-pollution episodes, in which the source contributions could be quite different from the monthly mean results, largely due to variations in meteorological conditions. To provide more insight into the control strategies for heavy pollution, we use the ERSM technique to investigate the source 
contribution features during three typical heavy-pollution episodes. We first select 47 heavy-pollution episodes over the BTH region during 2013-2015 (Table S7). Subsequently, we employ the Hybrid Single Particle Lagrangian Integrated Trajectory (HYSPLIT) model (Stein et al., 2015) and concentration weighted trajectory (CWT) method (Cheng et al., 2013) to identify the potential source regions for $\mathrm{PM}_{2.5}$ during each episode and categorize these episodes according to their source regions. We then select a representative episode from each of the three most important pollution types in which the air mass primarily originates from local areas ("Local" type), from the south ("South" type), and from the southeast ("Southeast" type). We give preference to episodes within the 4-month simulation period of this study to facilitate a comparison with the monthly mean source contribution features. For this reason, we select (1) 5-7 January 2014, (2) 7-11 October 2014, and (3) 29-31 October 2014 as representatives of the Local, South, and Southeast types. The selection of heavy-pollution episodes is detailed in Sect. S2.

Figure 8 shows the contribution of precursor and primary inorganic $\mathrm{PM}_{2.5}$ emissions from individual regions to $\mathrm{PM}_{2.5}$ concentrations during the three heavy-pollution episodes, and Fig. 9 illustrates the sensitivity of $\mathrm{PM}_{2.5}$ concentrations to the stepped control of individual pollutant-sector combinations. During 5-7 January 2014 (Local type), the contributions of local emission sources to $\mathrm{PM}_{2.5}$ concentrations far exceed those from other regions within BTH as well as from outside of BTH (Fig. 8). In contrast to the monthly mean results (Sect. 3.2), the contributions of primary inorganic $\mathrm{PM}_{2.5}$ emissions are comparable to, and even larger than, those of precursor emissions in the BTH region. The total contributions of primary $\mathrm{PM}_{2.5}$ (including POA) account for as much as $70-80 \%$ of the contributions of all pollutants within the BTH region, which highlights the crucial importance of primary $\mathrm{PM}_{2.5}$ controls during this episode. Moreover, the control of NMVOC, $\mathrm{NH}_{3}$, and $\mathrm{SO}_{2}$ emissions could contribute moderately to reducing $\mathrm{PM}_{2.5}$ concentrations. However, $\mathrm{NO}_{x}$ emission reduction induces an increase in $\mathrm{PM}_{2.5}$ concentrations, even at an $80 \%$ reduction ratio. Therefore, effective temporary control measures for this episode should focus on the control of local emissions, with emphasis laid on primary $\mathrm{PM}_{2.5}$.

During 7-11 October 2014 (South type), the contributions of emissions outside BTH to $\mathrm{PM}_{2.5}$ concentrations are as large as $33 \%$ in Beijing and $40-50 \%$ in other regions. Within the BTH region, the emissions from Southern Hebei can have similar effects to local emissions on $\mathrm{PM}_{2.5}$ concentrations in Beijing, indicating a strong long-range transport from the south. In addition, the total contributions of precursor emissions about double those of primary inorganic $\mathrm{PM}_{2.5}$ emissions. Among all precursors, $\mathrm{PM}_{2.5}$ concentrations are mainly sensitive to emissions of $\mathrm{NH}_{3}, \mathrm{NMVOC}+\mathrm{IVOC}$, and POA. The sensitivity of $\mathrm{PM}_{2.5}$ concentrations to $\mathrm{NO}_{x}$ emissions increases dramatically with reduction ratio. Although small $\mathrm{NO}_{x}$ reductions may slightly elevate $\mathrm{PM}_{2.5}$ concen- trations, large $\mathrm{NO}_{x}$ emission reduction $(>50 \%)$ can result in significant $\mathrm{PM}_{2.5}$ reduction. To effectively mitigate $\mathrm{PM}_{2.5}$ pollution during this episode, we should implement control measures for precursor emissions in both the BTH region (especially the southern part) and regions south of BTH. The $\mathrm{NO}_{x}$ emissions, if controlled, should be reduced by at least $50 \%$ to avoid adverse side effect.

For 29-31 October 2014 (Southeast type), $\mathrm{PM}_{2.5}$ concentrations are also significantly affected by emissions outside the BTH region. Within the BTH region, the $\mathrm{PM}_{2.5}$ concentrations in Beijing and Northern Hebei are about equally affected by local emissions and emissions from Eastern Hebei and Southern Hebei, while local emissions play dominant roles in other regions. The emissions of both precursor and primary inorganic $\mathrm{PM}_{2.5}$ within the $\mathrm{BTH}$ region make important contributions to $\mathrm{PM}_{2.5}$ concentrations, and the relative significance of the two is dependent on region. All precursors except $\mathrm{NO}_{x}$ can contribute considerably to $\mathrm{PM}_{2.5}$ reductions, and the sensitivity of $\mathrm{PM}_{2.5}$ to $\mathrm{NH}_{3}$ increases rapidly with emission ratio. $\mathrm{NO}_{x}$ emissions are negatively correlated with $\mathrm{PM}_{2.5}$ concentrations in most cases. Regarding the temporary control strategy for this episode, it is preferable to implement joint control of primary $\mathrm{PM}_{2.5}$ and precursors both within and outside the BTH region, with stringent measures over Eastern and Southern Hebei.

From the analysis above, we conclude that the source contributions are tremendously different in these three episodes, which have been demonstrated to represent some key features of the corresponding pollution types (Local, South, and Southeast types). Therefore, episode-specific control strategies need to be formulated based on the source contribution features of individual pollution types. Nevertheless, the results of this study are not yet sufficient to guide the development of temporary control strategies for all heavypollution episodes because the conclusions drawn from the three episodes may not be generalized to pollution types. In future studies, we need to simulate more episodes to improve their classification and to comprehensively understand the source contribution features of each pollution type. For a coming heavy-pollution episode, we can predict its pollution type using an air quality forecasting model and subsequently formulate the temporary control strategies based on the source contribution features of this specific pollution type.

\section{Conclusion and implications}

In the present study, we investigated the nonlinear response of $\mathrm{PM}_{2.5}$ concentrations to emission changes in multiple pollutants from different sectors and regions over the BTH region, using the ERSM technique coupled with the CMAQ/2D-VBS model.

Among all pollutants, primary inorganic $\mathrm{PM}_{2.5}$ makes the largest contribution (24-36\%) to the 4-month mean 


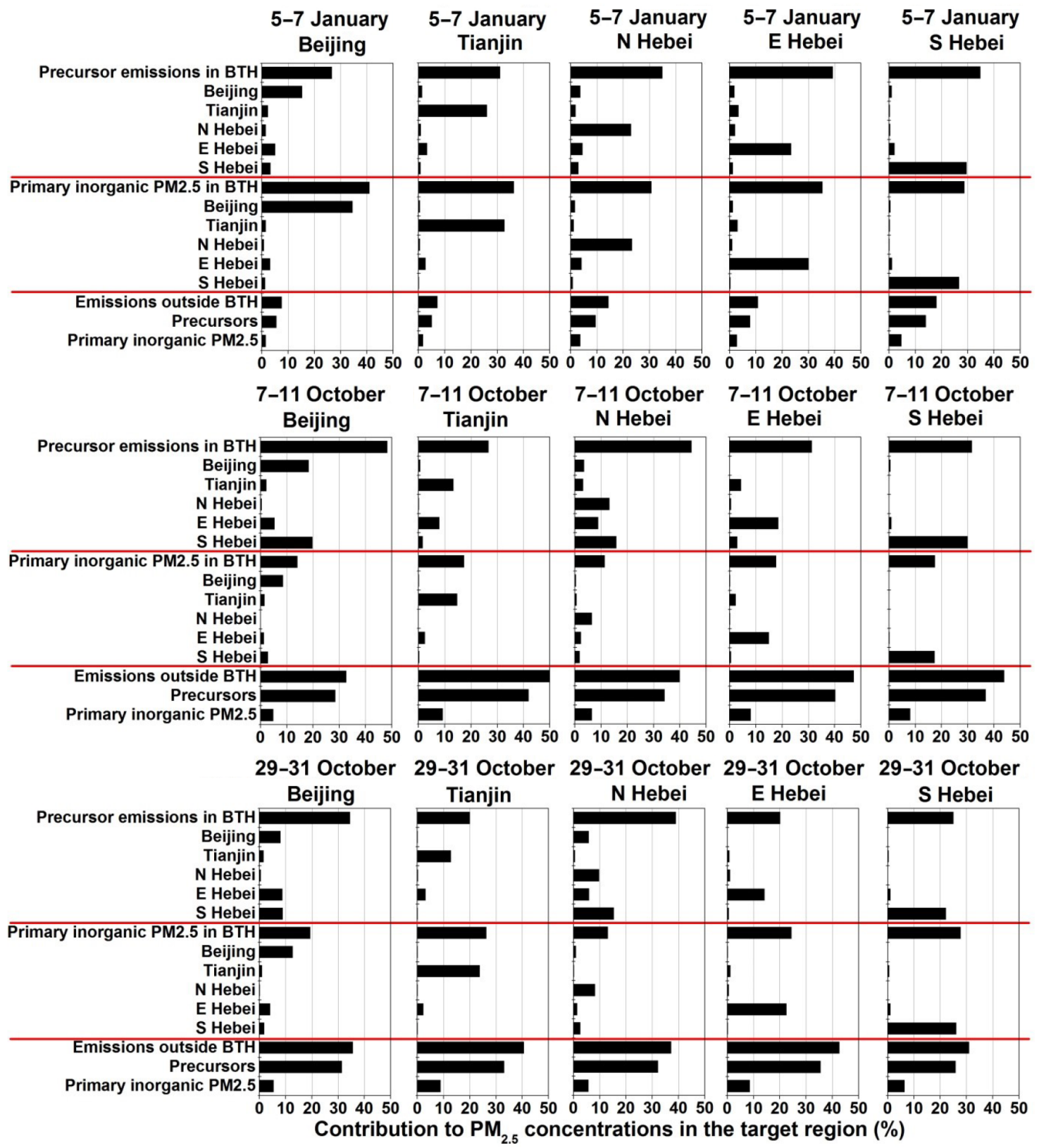

Figure 8. The contribution of precursor $\left(\mathrm{NO}_{x}, \mathrm{SO}_{2}, \mathrm{NH}_{3}, \mathrm{NMVOC}\right.$, IVOC, and POA) and primary inorganic $\mathrm{PM}_{2.5}$ emissions from individual regions to $\mathrm{PM}_{2.5}$ concentrations during three typical heavy-pollution episodes.

$\mathrm{PM}_{2.5}$ concentrations. The contribution from primary inorganic $\mathrm{PM}_{2.5}$ is especially high in heavily polluted winter and is dominated by the industry as well as residential and commercial sectors. The total contributions of all precursors to $\mathrm{PM}_{2.5}$ concentrations range between 31 and $48 \%$. Among the precursors, $\mathrm{PM}_{2.5}$ concentrations are primarily sensitive to the emissions of $\mathrm{NH}_{3}, \mathrm{NMVOC}+$ IVOC, and POA. With the increase in reduction ratio, the sensitivities of $\mathrm{PM}_{2.5}$ concentrations to pollutant emissions remain roughly constant for primary inorganic $\mathrm{PM}_{2.5}$ and $\mathrm{SO}_{2}$, increase substantially for $\mathrm{NH}_{3}$ and $\mathrm{NO}_{x}$, and decrease slightly for POA and NMVOC + IVOC. The contributions of primary inorganic $\mathrm{PM}_{2.5}$ emissions to $\mathrm{PM}_{2.5}$ concentrations are dominated by local emission sources, which account for over $75 \%$ of the total primary inorganic $\mathrm{PM}_{2.5}$ contributions. For precursors, however, emissions from other regions could play similar roles to local emission sources in the summer and over the northern part of BTH. Different $\mathrm{PM}_{2.5}$ chemical components are associated with distinct source contribution features. The $\mathrm{NO}_{3}^{-}$and $\mathrm{SO}_{4}^{2-}$ concentrations are the most sensitive to emissions of $\mathrm{NH}_{3}$ and $\mathrm{SO}_{2}$, respectively. The emissions of the POA and NMVOC + IVOC are two major 


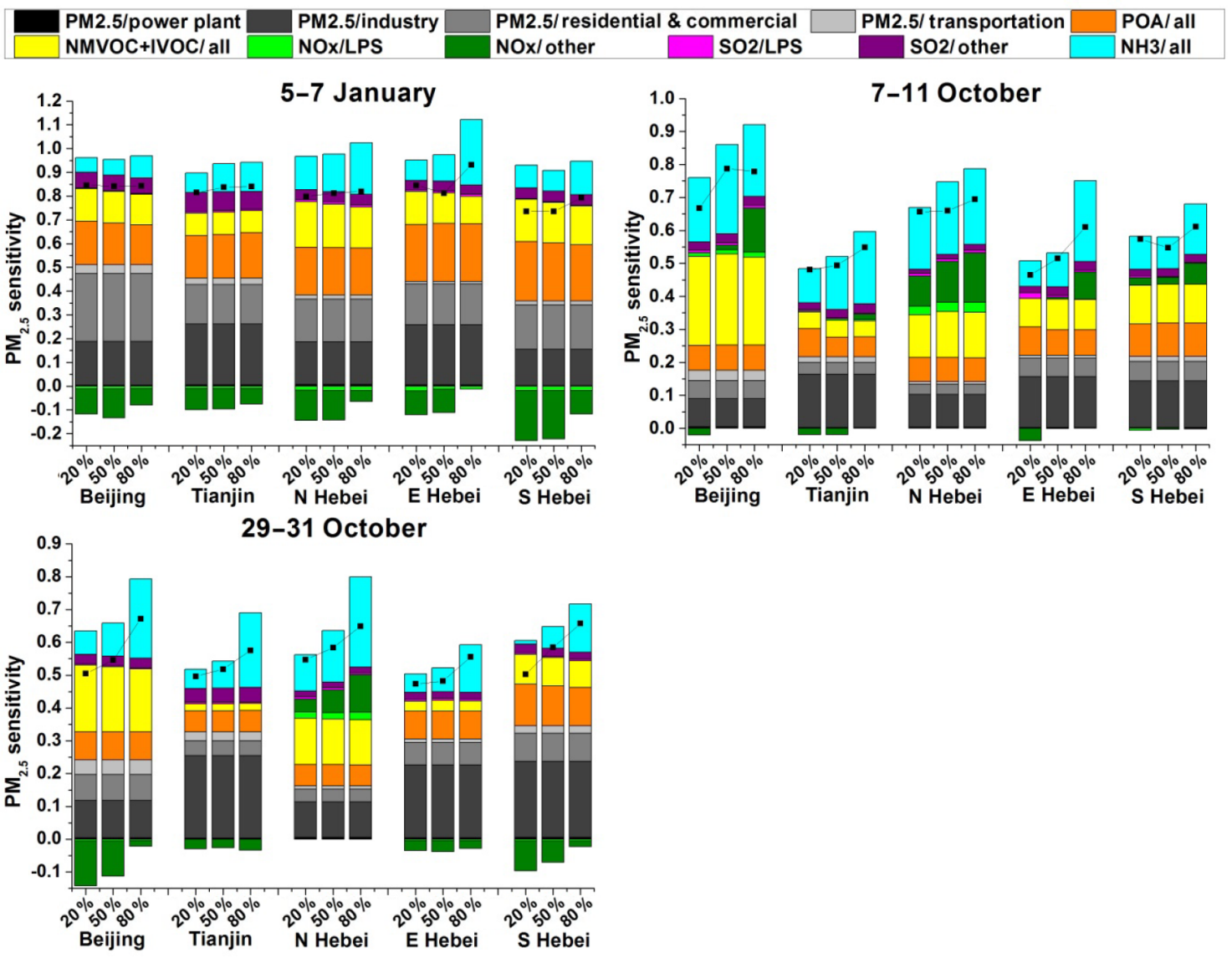

Figure 9. Sensitivity of $\mathrm{PM}_{2.5}$ concentrations to the stepped control of individual air pollutants from individual sectors during three heavypollution episodes. The meanings of $x$ axis, $y$ axis, colored bars, and black dotted lines are the same as in Fig. 4.

contributors to OA concentrations, with their relative importance depending on season.

The source contribution features are significantly different for three typical heavy-pollution episodes, which belong to three distinct pollution types. The $\mathrm{PM}_{2.5}$ concentrations in the first episode (Local type) are dominated by local sources and primary $\mathrm{PM}_{2.5}$ emissions, while the second episode (South type) is primarily affected by precursor emissions from local and southern regions. The third episode (Southeast type) is significantly influenced by emissions of both primary inorganic $\mathrm{PM}_{2.5}$ and precursors from multiple regions. Future investigations are needed to acquire generalized patterns for the source contributions of various heavypollution types.

The results of the present study have important implications for $\mathrm{PM}_{2.5}$ control policies over the BTH region. First, the control of primary $\mathrm{PM}_{2.5}$ emissions should be a priority in $\mathrm{PM}_{2.5}$ control strategies. Primary $\mathrm{PM}_{2.5}$, including primary inorganic $\mathrm{PM}_{2.5}$ and POA, contribute over half of the 4-month mean $\mathrm{PM}_{2.5}$ concentrations, which is even higher in the winter when heavy pollution frequently occurs. The industry sector and the residential and commercial sectors represent $85 \%$ of the total primary $\mathrm{PM}_{2.5}$ emissions and therefore should be the focus of primary $\mathrm{PM}_{2.5}$ controls. In particular, we should pay special attention to the residential and commercial sectors, which account for half of the total contribution of primary $\mathrm{PM}_{2.5}$ emissions to $\mathrm{PM}_{2.5}$ concentrations in the winter but have been frequently neglected in China's previous control policies. Second, the control policies for NMVOC and IVOC emissions should be strengthened. The sensitivity of $\mathrm{PM}_{2.5}$ concentrations to NMVOC + IVOC is one of the largest among all precursors. In particular, the control of NMVOC and IVOC emissions is very effective for $\mathrm{PM}_{2.5}$ reduction even at the initial control stage, as indicated by the large sensitivity at small reduction ratios. Moreover, NMVOC reduction is also crucial for the mitigation of $\mathrm{O}_{3}$ pollution considering an NMVOC-limited regime over the urban region and its surrounding areas (Xing et al., 2011). Third, $\mathrm{NO}_{x}$ emissions should be substantially reduced in both the BTH and other parts of China; in the long run, the reduction ratio should preferably approach their maximum feasible reduction levels. Fourth, more stringent control policies should be enforced in Southern Hebei, which on the one hand suffers from the most severe $\mathrm{PM}_{2.5}$ pollution 
(L. T. Wang et al., 2014) and, on the other hand, significantly affects both local and regional $\mathrm{PM}_{2.5}$ concentrations. Last but not least, considering the distinct source contributions in different heavy-pollution episodes, episode-specific temporary control strategies should be formulated according to the source contribution feature of the specific pollution type.

The present study has a few limitations. First, the establishment of ERSM requires several hundred or over 1000 emission scenarios, although the scenario number needed for a specific number of control variables has already been dramatically reduced as compared to the conventional RSM technique. Studies are needed to further reduce the scenario number but retain the accuracy of the ERSM technique. Second, the current ERSM is developed based on the meteorological conditions simulated for the base year and has not considered the impact of interannual variations in meteorological conditions on the relationships between emissions and $\mathrm{PM}_{2.5}$ concentrations. Third, although the ERSMpredicted responses of $\mathrm{PM}_{2.5}$ concentrations to precursor emissions have been demonstrated to agree well with chemical transport model simulations, evaluating the predicted responses against the actual situation in the real atmosphere still represents a major challenge because it is extremely difficult to artificially perturb emissions in the atmosphere. Last but not the least, the NMVOC and IVOC emissions have been lumped together in this study to reduce the number of control variables. Considering their differences in sources and SOA formation potentials (Jathar et al., 2014; Wu et al., 2017), a detailed quantification of the individual contributions of NMVOC and IVOC emissions from various sources to $\mathrm{PM}_{2.5}$ concentrations is required in the future to better inform NMVOC/IVOC control policies.

Data availability. All data needed to evaluate the conclusions in the paper are present in the paper and/or the Supplement. Additional data related to this paper can be requested from the authors.

\section{The Supplement related to this article is available online at https://doi.org/10.5194/acp-17-12031-2017- supplement.}

Competing interests. The authors declare that they have no conflict of interest.

Special issue statement. This article is part of the special issue "Regional transport and transformation of air pollution in eastern China”. It is not associated with a conference.

Acknowledgements. This research has been supported by the National Science Foundation of China (21625701 \& 21521064), the MOST National Key R \& D program (2016YFC0207601), the Strategic Pilot Project of Chinese Academy of Sciences (XDB05030401), the UCLA Sustainable Los Angeles Grand Challenge 2016 YZ-50958, and the Jet Propulsion Laboratory, California Institute of Technology, under contract with NASA. The simulations were completed on the "Explorer 100" cluster system of Tsinghua National Laboratory for Information Science and Technology.

Edited by: Jianmin Chen

Reviewed by: four anonymous referees

\section{References}

Burnett, R. T., Pope, C. A., Ezzati, M., Olives, C., Lim, S. S., Mehta, S., Shin, H. H., Singh, G., Hubbell, B., Brauer, M., Anderson, H. R., Smith, K. R., Balmes, J. R., Bruce, N. G., Kan, H. D., Laden, F., Pruss-Ustun, A., Michelle, C. T., Gapstur, S. M., Diver, W. R., and Cohen, A.: An Integrated Risk Function for Estimating the Global Burden of Disease Attributable to Ambient Fine Particulate Matter Exposure, Environ. Health Persp., 122, 397-403, https://doi.org/10.1289/Ehp.1307049, 2014.

Cai, S. Y., Wang, Y. J., Zhao, B., Wang, S. X., Chang, X., and Hao, J. M.: The impact of the "Air Pollution Prevention and Control Action Plan" on $\mathrm{PM}_{2.5}$ concentrations in Jing-Jin-Ji region during 2012-2020, Sci. Total Environ., 580, 197-209, https://doi.org/10.1016/j.scitotenv.2016.11.188, 2017.

Cheng, I., Zhang, L., Blanchard, P., Dalziel, J., and Tordon, R.: Concentration-weighted trajectory approach to identifying potential sources of speciated atmospheric mercury at an urban coastal site in Nova Scotia, Canada, Atmos. Chem. Phys., 13, 6031-6048, https://doi.org/10.5194/acp-13-6031-2013, 2013.

Cheng, Y. F., Zheng, G. J., Wei, C., Mu, Q., Zheng, B., Wang, Z. B., Gao, M., Zhang, Q., He, K. B., Carmichael, G., Pöschl, U., and $\mathrm{Su}, \mathrm{H}$.: Reactive nitrogen chemistry in aerosol water as a source of sulfate during haze events in China, Sci. Adv., 2, e1601530, https://doi.org/10.1126/sciadv.1601530, 2016.

Dong, X. Y., Li, J., Fu, J. S., Gao, Y., Huang, K., and Zhuang, G. S.: Inorganic aerosols responses to emission changes in Yangtze River Delta, China, Sci. Total Environ., 481, 522-532, https://doi.org/10.1016/j.scitotenv.2014.02.076, 2014.

Fu, X., Wang, S. X., Zhao, B., Xing, J., Cheng, Z., Liu, H., and Hao, J. M.: Emission inventory of primary pollutants and chemical speciation in 2010 for the Yangtze River Delta region, China, Atmos. Environ., 70, 39-50, https://doi.org/10.1016/j.atmosenv.2012.12.034, 2013.

Fu, X., Wang, S. X., Chang, X., Cai, S. Y., Xing, J., and Hao, J. M.: Modeling analysis of secondary inorganic aerosols over China: pollution characteristics, and meteorological and dust impacts, Sci. Rep.-UK, 6, 35992, https://doi.org/10.1038/srep35992, 2016.

Gordon, T. D., Presto, A. A., May, A. A., Nguyen, N. T., Lipsky, E. M., Donahue, N. M., Gutierrez, A., Zhang, M., Maddox, C., Rieger, P., Chattopadhyay, S., Maldonado, H., Maricq, M. M., and Robinson, A. L.: Secondary organic aerosol formation exceeds primary particulate matter emissions for lightduty gasoline vehicles, Atmos. Chem. Phys., 14, 4661-4678, https://doi.org/10.5194/acp-14-4661-2014, 2014a. 
Gordon, T. D., Presto, A. A., Nguyen, N. T., Robertson, W. H., Na, K., Sahay, K. N., Zhang, M., Maddox, C., Rieger, P., Chattopadhyay, S., Maldonado, H., Maricq, M. M., and Robinson, A. L.: Secondary organic aerosol production from diesel vehicle exhaust: impact of aftertreatment, fuel chemistry and driving cycle, Atmos. Chem. Phys., 14, 4643-4659, https://doi.org/10.5194/acp-14-4643-2014, 2014b.

Guenther, A., Karl, T., Harley, P., Wiedinmyer, C., Palmer, P. I., and Geron, C.: Estimates of global terrestrial isoprene emissions using MEGAN (Model of Emissions of Gases and Aerosols from Nature), Atmos. Chem. Phys., 6, 3181-3210, https://doi.org/10.5194/acp-6-3181-2006, 2006.

Hakami, A., Seinfeld, J. H., Chai, T. F., Tang, Y. H., Carmichael, G. R., and Sandu, A.: Adjoint sensitivity analysis of ozone nonattainment over the continental United States, Environ. Sci. Technol., 40, 3855-3864, https://doi.org/10.1021/Es052135g, 2006.

Han, X., Zhang, M. G., Zhu, L. Y., and Skorokhod, A.: Assessment of the impact of emissions reductions on air quality over North China Plain, Atmos. Pollut. Res., 7, 249-259, https://doi.org/10.1016/j.apr.2015.09.009, 2016.

Hennigan, C. J., Miracolo, M. A., Engelhart, G. J., May, A. A., Presto, A. A., Lee, T., Sullivan, A. P., McMeeking, G. R., Coe, H., Wold, C. E., Hao, W.-M., Gilman, J. B., Kuster, W. C., de Gouw, J., Schichtel, B. A., Collett Jr., J. L., Kreidenweis, S. M., and Robinson, A. L.: Chemical and physical transformations of organic aerosol from the photo-oxidation of open biomass burning emissions in an environmental chamber, Atmos. Chem. Phys., 11, 7669-7686, https://doi.org/10.5194/acp11-7669-2011, 2011.

Iman, R. L., Davenport, J. M., and Zeigler, D. K.: Latin Hypercube Sampling (Program User's Guide), Sandia National Laboratories, Albuquerque, NM, U.S., 78 pp., 1980.

IPCC: Climate Change 2013: The Physical Science Basis. Contribution of Working Group I to the Fifth Assessment Report of the Intergovernmental Panel on Climate Change, edited by: Stocker, T. F., Qin, D., Plattner, G.-K., Tignor, M., Allen, S. K., Boschung, J., Nauels, A., Xia, Y., Bex, V., and Midgley, P. M., Cambridge University Press, Cambridge, United Kingdom and New York, NY, USA, 1535 pp., 2013.

Jathar, S. H., Gordon, T. D., Hennigan, C. J., Pye, H. O. T., Pouliot, G., Adams, P. J., Donahue, N. M., and Robinson, A. L.: Unspeciated organic emissions from combustion sources and their influence on the secondary organic aerosol budget in the United States, P. Natl. Acad. Sci. USA, 111, 10473-10478, https://doi.org/10.1073/pnas.1323740111, 2014.

Jia, Y. T., Rahn, K. A., He, K. B., Wen, T. X., and Wang, Y. S.: A novel technique for quantifying the regional component of urban aerosol solely from its sawtooth cycles, J. Geophys. Res.-Atmos., 113, D21309, https://doi.org/10.1029/2008jd010389, 2008.

Li, J. W. and Han, Z. W.: A modeling study of severe winter haze events in Beijing and its neighboring regions, Atmos. Res., 170, 87-97, https://doi.org/10.1016/j.atmosres.2015.11.009, 2016.

Li, M., Zhang, Q., Kurokawa, J.-I., Woo, J.-H., He, K., Lu, Z., Ohara, T., Song, Y., Streets, D. G., Carmichael, G. R., Cheng, Y., Hong, C., Huo, H., Jiang, X., Kang, S., Liu, F., Su, H., and Zheng, B.: MIX: a mosaic Asian anthropogenic emission inventory under the international collaboration framework of the MICS-Asia and HTAP, Atmos. Chem. Phys., 17, 935-963, https://doi.org/10.5194/acp-17-935-2017, 2017.
Li, X., Zhang, Q., Zhang, Y., Zheng, B., Wang, K., Chen, Y., Wallington, T. J., Han, W. J., Shen, W., Zhang, X. Y., and He, K. B.: Source contributions of urban PM2.5 in the Beijing-TianjinHebei region: Changes between 2006 and 2013 and relative impacts of emissions and meteorology, Atmos Environ, 123, 229239, https://doi.org/10.1016/j.atmosenv.2015.10.048, 2015.

Lim, S. S., Vos, T., Flaxman, A. D., Danaei, G., Shibuya, K., AdairRohani, H., AlMazroa, M. A., Amann, M., Anderson, H. R., Andrews, K. G., Aryee, M., Atkinson, C., Bacchus, L. J., Bahalim, A. N., Balakrishnan, K., Balmes, J., Barker-Collo, S., Baxter, A., Bell, M. L., Blore, J. D., Blyth, F., Bonner, C., Borges, G., Bourne, R., Boussinesq, M., Brauer, M., Brooks, P., Bruce, N. G., Brunekreef, B., Bryan-Hancock, C., Bucello, C., Buchbinder, R., Bull, F., Burnett, R. T., Byers, T. E., Calabria, B., Carapetis, J., Carnahan, E., Chafe, Z., Charlson, F., Chen, H., Chen, J. S., Cheng, A. T.-A., Child, J. C., Cohen, A., Colson, K. E., Cowie, B. C., Darby, S., Darling, S., Davis, A., Degenhardt, L., Dentener, F., Des Jarlais, D. C., Devries, K., Dherani, M., Ding, E. L., Dorsey, E. R., Driscoll, T., Edmond, K., Ali, S. E., Engell, R. E., Erwin, P. J., Fahimi, S., Falder, G., Farzadfar, F., Ferrari, A., Finucane, M. M., Flaxman, S., Fowkes, F. G. R., Freedman, G., Freeman, M. K., Gakidou, E., Ghosh, S., Giovannucci, E., Gmel, G., Graham, K., Grainger, R., Grant, B., Gunnell, D., Gutierrez, H. R., Hall, W., Hoek, H. W., Hogan, A., Hosgood Iii, H. D., Hoy, D., Hu, H., Hubbell, B. J., Hutchings, S. J., Ibeanusi, S. E., Jacklyn, G. L., Jasrasaria, R., Jonas, J. B., Kan, H., Kanis, J. A., Kassebaum, N., Kawakami, N., Khang, Y.-H., Khatibzadeh, S., Khoo, J.-P., Kok, C., Laden, F., Lalloo, R., Lan, Q., Lathlean, T., Leasher, J. L., Leigh, J., Li, Y., Lin, J. K., Lipshultz, S. E., London, S., Lozano, R., Lu, Y., Mak, J., Malekzadeh, R., Mallinger, L., Marcenes, W., March, L., Marks, R., Martin, R., McGale, P., McGrath, J., Mehta, S., Memish, Z. A., Mensah, G. A., Merriman, T. R., Micha, R., Michaud, C., Mishra, V., Hanafiah, K. M., Mokdad, A. A., Morawska, L., Mozaffarian, D., Murphy, T., Naghavi, M., Neal, B., Nelson, P. K., Nolla, J. M., Norman, R., Olives, C., Omer, S. B., Orchard, J., Osborne, R., Ostro, B., Page, A., Pandey, K. D., Parry, C. D. H., Passmore, E., Patra, J., Pearce, N., Pelizzari, P. M., Petzold, M., Phillips, M. R., Pope, D., Pope Iii, C. A., Powles, J., Rao, M., Razavi, H., Rehfuess, E. A., Rehm, J. T., Ritz, B., Rivara, F. P., Roberts, T., Robinson, C., RodriguezPortales, J. A., Romieu, I., Room, R., Rosenfeld, L. C., Roy, A., Rushton, L., Salomon, J. A., Sampson, U., Sanchez-Riera, L., Sanman, E., Sapkota, A., Seedat, S., Shi, P., Shield, K., Shivakoti, R., Singh, G. M., Sleet, D. A., Smith, E., Smith, K. R., Stapelberg, N. J. C., Steenland, K., Stöckl, H., Stovner, L. J., Straif, K., Straney, L., Thurston, G. D., Tran, J. H., Van Dingenen, R., van Donkelaar, A., Veerman, J. L., Vijayakumar, L., Weintraub, R., Weissman, M. M., White, R. A., Whiteford, H., Wiersma, S. T., Wilkinson, J. D., Williams, H. C., Williams, W., Wilson, N., Woolf, A. D., Yip, P., Zielinski, J. M., Lopez, A. D., Murray, C. J. L., and Ezzati, M.: A comparative risk assessment of burden of disease and injury attributable to 67 risk factors and risk factor clusters in 21 regions, 1990-2010: a systematic analysis for the Global Burden of Disease Study 2010, Lancet, 380, 2224-2260, https://doi.org/10.1016/S0140-6736(12)61766-8, 2012.

Liu, J., Mauzerall, D. L., Chen, Q., Zhang, Q., Song, Y., Peng, W., Klimont, Z., Qiu, X. H., Zhang, S. Q., Hu, M., Lin, W. L., Smith, K. R., and Zhu, T.: Air pollutant emissions from Chinese households: A major and underappreciated ambient 
pollution source, P. Natl. Acad. Sci. USA, 113, 7756-7761, https://doi.org/10.1073/pnas.1604537113, 2016.

Lv, L. Y. and Li, H. Y.: Economic evaluation of the health effect of $\mathrm{PM}_{10}$ and $\mathrm{PM}_{2.5}$ pollution over the Beijing-Tianjin-Hebei region, Acta Scientiarum Naturalium Universitatis Nankaiensis, 69-77, 2016.

Qin, Y. and Xie, S. D.: Historical estimation of carbonaceous aerosol emissions from biomass open burning in China for the period 1990-2005, Environ. Pollut., 159, 3316-3323, https://doi.org/10.1016/j.envpol.2011.08.042, 2011.

Russell, A., Milford, J., Bergin, M. S., Mcbride, S., Mcnair, L., Yang, Y., Stockwell, W. R., and Croes, B.: Urban Ozone Control and Atmospheric Reactivity of Organic Gases, Science, 269, 491-495, https://doi.org/10.1126/science.269.5223.491, 1995.

Sandu, A., Daescu, D. N., Carmichael, G. R., and Chai, T. F.: Adjoint sensitivity analysis of regional air quality models, J. Comput. Phys., 204, 222-252, https://doi.org/10.1016/j.jcp.2004.10.011, 2005.

Santner, T. J., Williams, B. J., and Notz, W.: The Design and Analysis of Computer Experiments, Springer Verlag, New York, USA, 283 pp., 2003.

Seinfeld, J. H., Bretherton, C., Carslaw, K. S., Coe, H., DeMott, P. J., Dunlea, E. J., Feingold, G., Ghan, S., Guenther, A. B., Kahn, R., Kraucunas, I., Kreidenweis, S. M., Molina, M. J., Nenes, A., Penner, J. E., Prather, K. A., Ramanathan, V., Ramaswamy, V., Rasch, P. J., Ravishankara, A. R., Rosenfeld, D., Stephens, G., and Wood, R.: Improving our fundamental understanding of the role of aerosol-cloud interactions in the climate system, P. Natl. Acad. Sci. USA, 113, 5781-5790, https://doi.org/10.1073/pnas.1514043113, 2016.

Stein, A. F., Draxler, R. R., Rolph, G. D., Stunder, B. J. B., Cohen, M. D., and Ngan, F.: NOAA's HYSPLIT atmospheric transport and dispersion modeling system, B. Am. Meteorol. Soc., 96, 2059-2077, https://doi.org/10.1175/bams-d-14-00110.1, 2015.

Streets, D. G., Fu, J. S., Jang, C. J., Hao, J. M., He, K. B., Tang, X. Y., Zhang, Y. H., Wang, Z. F., Li, Z. P., and Zhang, Q.: Air quality during the 2008 Beijing Olympic Games, Atmos. Environ., 41, 480-492, https://doi.org/10.1016/j.atmosenv.2006.08.046, 2007.

The State Council of the People's Republic of China: Notice to issue the "Air Pollution Prevention and Control Action Plan": http://www.gov.cn/zwgk/2013-09/12/content_2486773.htm (last access: 9 September 2016), 2013.

U.S. Environmental Protection Agency: Technical support document for the proposed PM NAAQS rule: Response Surface Modeling[R/OL], http://www.epa.gov/scram001/reports/pmnaaqs_ tsd_rsm_all_021606.pdf (last access: 1 February 2015), 2006.

van Donkelaar, A., Martin, R. V., Brauer, M., and Boys, B. L.: Use of satellite observations for long-term exposure assessment of global concentrations of fine particulate matter, Environmen. Health Persp., 123, 135-143, https://doi.org/10.1289/ehp.1408646, 2015.

Wang, G. H., Zhang, R. Y., Gomez, M. E., Yang, L. X., Zamora, M. L., Hu, M., Lin, Y., Peng, J. F., Guo, S., Meng, J. J., Li, J. J., Cheng, C. L., Hu, T. F., Ren, Y. Q., Wang, Y. S., Gao, J., Cao, J. J., An, Z. S., Zhou, W. J., Li, G. H., Wang, J. Y., Tian, P. F., Marrero-Ortiz, W., Secrest, J., Du, Z. F., Zheng, J., Shang, D. J., Zeng, L. M., Shao, M., Wang, W. G., Huang, Y., Wang, Y., Zhu, Y. J., Li, Y. X., Hu, J. X., Pan, B., Cai, L., Cheng, Y. T., Ji, Y. M., Zhang, F., Rosenfeld, D., Liss, P. S., Duce, R. A., Kolb, C. E., and Molina, M. J.: Persistent sulfate formation from London Fog to Chinese haze, P. Natl. Acad. Sci. USA, 113, 13630-13635, https://doi.org/10.1073/pnas.1616540113, 2016.

Wang, J. D., Wang, S. X., Jiang, J. K., Ding, A. J., Zheng, M., Zhao, B., Wong, D. C., Zhou, W., Zheng, G. J., Wang, L., Pleim, J. E., and Hao, J. M.: Impact of aerosol-meteorology interactions on fine particle pollution during China's severe haze episode in January 2013, Environ. Res. Lett., 9, 094002, https://doi.org/10.1088/1748-9326/9/9/094002, 2014.

Wang, J. D., Xing, J., Mathur, R., Pleim, J. E., Wang, S. X., Hogrefe, C., Gan, C.-M., Wong, D. C., and Hao, J. M.: Historical Trends in $\mathrm{PM}_{2.5}$-Related Premature Mortality during 1990-2010 across the Northern Hemisphere, Environ. Health Persp., 125, 400-408, https://doi.org/10.1289/EHP298, 2017.

Wang, J. D., Zhao, B., Wang, S. X., Yang, F. M., Xing, J., Morawska, L., Ding, A. J., Kulmala, M., Kerminen, V. M., Kujansuu, J., Wang, Z. F., Ding, D. A., Zhang, X. Y., Wang, H. B., Tian, M., Petaja, T., Jiang, J. K., and Hao, J. M.: Particulate matter pollution over China and the effects of control policies, Sci. Total Environ., 584, 426-447, https://doi.org/10.1016/j.scitotenv.2017.01.027, 2017.

Wang, L. T., Hao, J. M., He, K. B., Wang, S. X., Li, J. H., Zhang, Q., Streets, D. G., Fu, J. S., Jang, C. J., Takekawa, H., and Chatani, S.: A modeling study of coarse particulate matter pollution in Beijing: Regional source contributions and control implications for the 2008 summer Olympics, J Air Waste Manage., 58, 1057 1069, https://doi.org/10.3155/1047-3289.58.8.1057, 2008.

Wang, L. T., Jang, C., Zhang, Y., Wang, K., Zhang, Q. A., Streets, D., Fu, J., Lei, Y., Schreifels, J., He, K. B., Hao, J. M., Lam, Y. F., Lin, J., Meskhidze, N., Voorhees, S., Evarts, D., and Phillips, S.: Assessment of air quality benefits from national air pollution control policies in China. Part II: Evaluation of air quality predictions and air quality benefits assessment, Atmos. Environ., 44, 3449-3457, https://doi.org/10.1016/j.atmosenv.2010.05.058, 2010.

Wang, L. T., Wei, Z., Yang, J., Zhang, Y., Zhang, F. F., Su, J., Meng, C. C., and Zhang, Q.: The 2013 severe haze over southern Hebei, China: model evaluation, source apportionment, and policy implications, Atmos. Chem. Phys., 14, 3151-3173, https://doi.org/10.5194/acp-14-3151-2014, 2014.

Wang, S. X. and Zhang, C. Y.: Spatial and temporal distribution of air pollutant emissions from open burning of crop residues in China, Sciencepaper Online, 3, 1-6, 2008.

Wang, S. X., Xing, J., Jang, C. R., Zhu, Y., Fu, J. S., and Hao, J. M.: Impact assessment of ammonia emissions on inorganic aerosols in east China using response surface modeling technique, Environ. Sci. Technol., 45, 9293-9300, https://doi.org/10.1021/Es2022347, 2011.

Wang, S. X., Zhao, B., Cai, S. Y., Klimont, Z., Nielsen, C. P., Morikawa, T., Woo, J. H., Kim, Y., Fu, X., Xu, J. Y., Hao, J. M., and He, K. B.: Emission trends and mitigation options for air pollutants in East Asia, Atmos. Chem. Phys., 14, 6571-6603, https://doi.org/10.5194/acp-14-6571-2014, 2014

Wang, S. X., Zhao, B., Wu, Y., and Hao, J. M.: Target and measures to prevent and control ambient fine particle pollution in China, Chinese J. Environ. Manage., 7, 37-43, 2015.

Wang, Y. J., Bao, S. W., Wang, S. X., Hu, Y. T., Shi, X., Wang, J. D., Zhao, B., Jiang, J. K., Zheng, M., Wu, M. H., Russell, A. G., Wang, Y. H., and Hao, J. M.: Local and regional contributions to 
fine particulate matter in Beijing during heavy haze episodes, Sci. Total Environ., https://doi.org/10.1016/j.scitotenv.2016.12.127, in press, 2016.

Wu, W. J.: Health Effect Attributed to Ambient Fine Particle Pollution in the Beijing-Tianjin-Hebei Region and its Source Apportionment, MS thesis, School of Environment, Tsinghua University, Beijing, China, 98 pp., 2016.

Wu, W. J., Zhao, B., Wang, S. X., and Hao, J. M.: Ozone and secondary organic aerosol formation potential from anthropogenic volatile organic compounds emissions in China, J. Environ. Sci., 53, 224-237, https://doi.org/10.1016/j.jes.2016.03.025, 2017.

Xing, J., Wang, S. X., Jang, C., Zhu, Y., and Hao, J. M.: Nonlinear response of ozone to precursor emission changes in China: a modeling study using response surface methodology, Atmos. Chem. Phys., 11, 5027-5044, https://doi.org/10.5194/acp-115027-2011, 2011.

Yang, Y. J., Wilkinson, J. G., and Russell, A. G.: Fast, direct sensitivity analysis of multidimensional photochemical models, Environ. Sci. Technol., 31, 2859-2868, https://doi.org/10.1021/Es970117w, 1997.

Ying, Q., Wu, L., and Zhang, H. L.: Local and inter-regional contributions to $\mathrm{PM}_{2.5}$ nitrate and sulfate in China, Atmos. Environ., 94, 582-592, https://doi.org/10.1016/j.atmosenv.2014.05.078, 2014.

Yu, L. D., Wang, G. F., Zhang, R. J., Zhang, L. M., Song, Y., Wu, B. B., Li, X. F., An, K., and Chu, J. H.: Characterization and Source Apportionment of $\mathrm{PM}_{2.5}$ in an Urban Environment in Beijing, Aerosol Air Qual. Res., 13, 574-583, https://doi.org/10.4209/aaqr.2012.07.0192, 2013.

Zhang, L., Shao, J. Y., Lu, X., Zhao, Y. H., Hu, Y. Y., Henze, D. K., Liao, H., Gong, S. L., and Zhang, Q.: Sources and Processes Affecting Fine Particulate Matter Pollution over North China: An Adjoint Analysis of the Beijing APEC Period, Environ. Sci. Technol., 50, 8731-8740, https://doi.org/10.1021/acs.est.6b03010, 2016.

Zhang, W., Guo, J. H., Sun, Y. L., Yuan, H., Zhuang, G. S., Zhuang, Y. H., and Hao, Z. P.: Source apportionment for,urban $\mathrm{PM}_{10}$ and $\mathrm{PM}_{2.5}$ in the Beijing area, Chinese Sci. Bull., 52, 608-615, https://doi.org/10.1007/s11434-007-0076-5, 2007.

Zhao, B., Wang, S. X., Dong, X. Y., Wang, J. D., Duan, L., Fu, X., Hao, J. M., and Fu, J.: Environmental effects of the recent emission changes in China: implications for particulate matter pollution and soil acidification, Environ. Res. Lett., 8, 024031, https://doi.org/10.1088/1748-9326/8/2/024031, $2013 \mathrm{a}$.

Zhao, B., Wang, S. X., Liu, H., Xu, J. Y., Fu, K., Klimont, Z., Hao, J. M., He, K. B., Cofala, J., and Amann, M.: NOx emissions in China: historical trends and future perspectives, Atmos. Chem. Phys., 13, 9869-9897, https://doi.org/10.5194/acp13-9869-2013, 2013b.
Zhao, B., Wang, S. X., Wang, J. D., Fu, J. S., Liu, T. H., Xu, J. Y., Fu, $\mathrm{X}$., and Hao, J. M.: Impact of national $\mathrm{NO}_{x}$ and $\mathrm{SO}_{2}$ control policies on particulate matter pollution in China, Atmos. Environ., 77, 453-463, https://doi.org/10.1016/j.atmosenv.2013.05.012, 2013c.

Zhao, B., Wang, S. X., Donahue, N. M., Chuang, W., Hildebrandt Ruiz, L., Ng, N. L., Wang, Y. J., and Hao, J. M.: Evaluation of one-dimensional and two-dimensional volatility basis sets in simulating the aging of secondary organic aerosols with smogchamber experiments, Environ. Sci. Technol., 49, 2245-2254, https://doi.org/10.1021/es5048914, 2015a.

Zhao, B., Wang, S. X., Xing, J., Fu, K., Fu, J. S., Jang, C., Zhu, Y., Dong, X. Y., Gao, Y., Wu, W. J., Wang, J. D., and Hao, J. M.: Assessing the nonlinear response of fine particles to precursor emissions: development and application of an extended response surface modeling technique v1.0, Geosci. Model Dev., 8, 115128, https://doi.org/10.5194/gmd-8-115-2015, 2015 b.

Zhao, B., Wang, S. X., Donahue, N. M., Jathar, S. H., Huang, X. F., Wu, W. J., Hao, J. M., and Robinson, A. L.: Quantifying the effect of organic aerosol aging and intermediate-volatility emissions on regional-scale aerosol pollution in China, Sci. Rep.-UK, 6, 28815, https://doi.org/10.1038/srep28815, 2016.

Zhao, B., Liou, K.-N., Gu, Y., Jiang, J. H., Li, Q., Fu, R., Huang, L., Liu, X., Shi, X., Su, H., and He, C.: A water vapor modulated aerosol impact on ice crystal size, Atmos. Chem. Phys. Discuss., https://doi.org/10.5194/acp-2017-548, in review, 2017a.

Zhao, B., Liou, K. N., Gu, Y., Li, Q. B., Jiang, J. H., Su, H., He, C. L., Tseng, H. L. R., Wang, S. X., Liu, R., Qi, L., Lee, W. L., and Hao, J. M.: Enhanced $\mathrm{PM}_{2.5}$ pollution in China due to aerosol-cloud interactions, Sci. Rep.-UK, 7, 4453, https://doi.org/10.1038/s41598-017-04096-8, 2017b.

Zhao, Y., Wang, S. X., Duan, L., Lei, Y., Cao, P. F., and Hao, J. M.: Primary air pollutant emissions of coal-fired power plants in China: Current status and future prediction, Atmos. Environ., 42, 8442-8452, https://doi.org/10.1016/j.atmosenv.2008.08.021, 2008.

Zheng, G. J., Duan, F. K., Su, H., Ma, Y. L., Cheng, Y., Zheng, B., Zhang, Q., Huang, T., Kimoto, T., Chang, D., Pöschl, U., Cheng, Y. F., and He, K. B.: Exploring the severe winter haze in Beijing: the impact of synoptic weather, regional transport and heterogeneous reactions, Atmos. Chem. Phys., 15, 2969-2983, https://doi.org/10.5194/acp-15-2969-2015, 2015. 